\title{
ENVIRONMENTAL APPLICATIONS OF PRESSURISED FLUID EXTRACTION
}

\author{
Lisa J. Fitzpatrick*, Olatz Zuloaga+, Nestor Etxebarria+ \\ and John R. Dean*! \\ * School of Applied and Molecular Sciences, University of \\ Northumbria at Newcastle, Ellison Building, Newcastle upon Tyne, \\ NEl 8ST, UK. \\ ${ }^{+}$Kimika Analitikoa Saila, Euskal Herriko Unibertsitatea, P.K. 644, \\ E-48080, Bilbao.
}

\section{CONTENTS:}

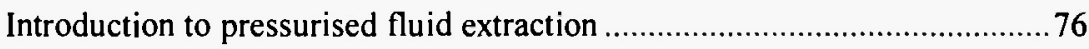

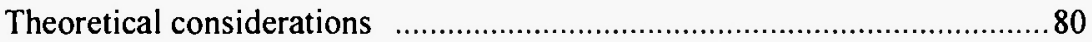

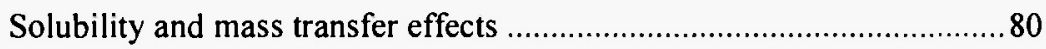

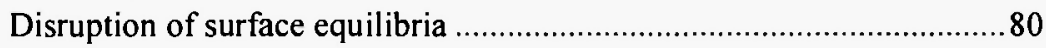

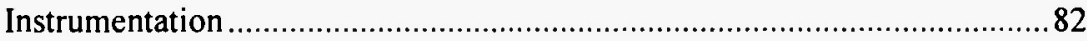

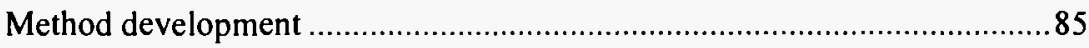

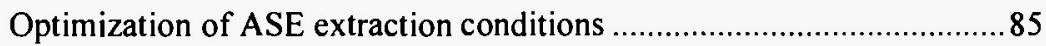

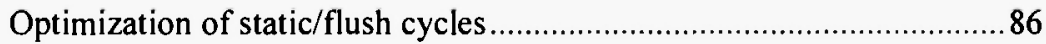

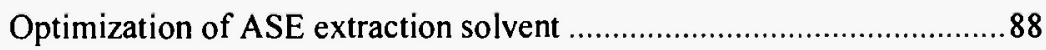

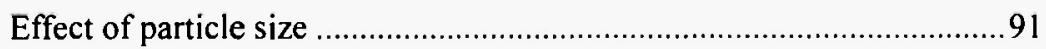

Proposal for PFE method development..............................................92

Applications of PFE

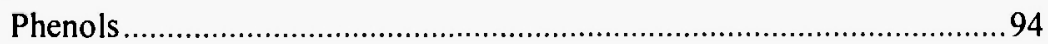

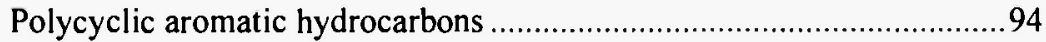

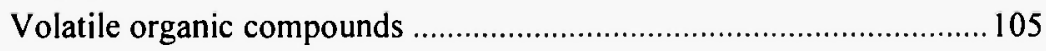

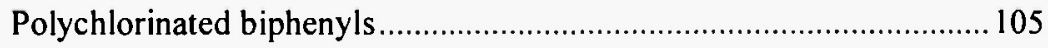

Dioxins and dibenzofurans............................................................. 110

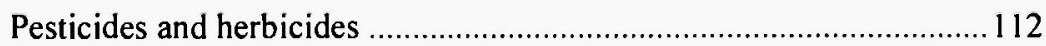

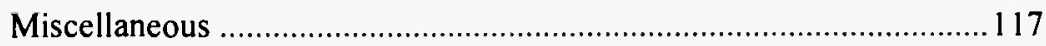

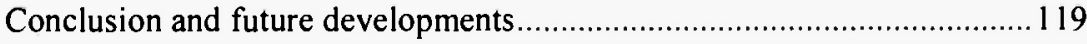

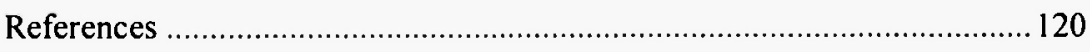

'Author for correspondence 


\section{SUMMARY}

Pressurised fluid extraction (PFE) utilises organic solvent under high pressure and temperature for the extraction of organic compounds from environmental matrices. This review considers the theoretical aspects and instrumentation required to perform PFE. An important aspect of any new extraction technique is method development. As well as considering important aspects of method development for PFE, a procedure is highlighted for the development of a quantitative extraction protocol. Applications of PFE for the removal of phenols, polycyclic aromatic hydrocarbons, volatile organic compounds, polychlorinated biphenyls, dioxins and dibenzofurans, pesticides and herbicides are considered. Typical solid environmental matrices from which these analytes are removed are soils, sediments, fly ash, biological matrices (pine needles, mosses, fish and mussel tissue) and foodstuffs. Finally, future directions of the technique are considered.

\section{INTRODUCTION TO PRESSURISED FLUID EXTRACTION}

The name pressurised fluid extraction (PFE) has become the generic name for the extraction technique originally launched by Dionex Inc., in spring 1995, called accelerated solvent extraction (ASE ${ }^{\mathrm{TM}}$ ). The technique relies on the use of temperature and pressure to extract organic and organometallic compounds from matrices (environmental, industrial and food). The use of moderate temperature and high pressure for the extraction of organic compounds is however not new, as the process has previously been exploited in supercritical fluid extraction for the same purpose. The main difference being that in SFE the process relies on the use of carbon dioxide, in the supercritical state i.e. above $31.1^{\circ} \mathrm{C}$ and $1070.4 \mathrm{psi}(74.8 \mathrm{~atm})$, to extract the organic compounds of interest. The lack of a dipole moment for $\mathrm{CO}_{2}$ means that its ability to extract moderately polar and polar compounds is limited. This is circumvented by the addition of an organic modifier, typically methanol, in the $1-10 \%, v / v$ range. PFE can be viewed as an extension of the SFE technique in which the $\mathrm{CO}_{2}$ is replaced in its entirety by an organic solvent or mixture. The selection of the most effective organic solvent is often based on previous experience, manufacturer's guidelines or standard methods. In the case of the latter this corresponds to the USA-EPA method $3545 / 1 /$. The EPA method 3545 was developed for application to the 
following compounds classes: base, neutral, acids (BNA); organochlorine pesticides (OCPs); organophosphorus compounds (OPPs); chlorinated herbicides; and PCBs. Examples of individual compounds representative of the different classes are shown in Table 1. The choice of extraction solvent,

Table 1

Compounds included in EPA Method 3545

BNAS

\begin{tabular}{|l|l|l|}
\hline Phenol & Bis(2-chloroisopropyl)ether & 4-nitrophenol \\
\hline 2-chlorophenol & Isophorone & Dibenzofuran \\
\hline 1,4-dichlorobenzene & 2-nitrophenol & N-Nitrosodiphenylamine \\
\hline 2-methylphenol & Bis(chlorethoxy)methane & Hexachlorobenzene \\
\hline o-toluidine & 1,2,4-trichlorobenzene & Phenanthrene \\
\hline Hexachloroethane & 4-chloroaniline & Carbazole \\
\hline 2,4-dimethylphenol & 4-chloro-3-methylphenol & Pyrene \\
\hline Bis(2-chloroethyl)ether & Hexachlorocyclopentadiene & Benz[a]anthracene \\
\hline 1,3-dichlorobenzene & 2,4,5-trichlorophenol & Benzo[b]fluoranthene \\
\hline 1,2-dichlorobenzene & 2-nitroaniline & Benzo[a]pyrene \\
\hline 2,4-dichlorophenol & 2,4-dinitrotoluene & Dibenz[a,h]anthracene \\
\hline Naphthalene & 4-nitroaniline & Nitrobenzene \\
\hline Hexachlorobutadiene & 4-bromophenyl-phenylether & 3-nitroaniline \\
\hline 2-methylnaphthalene & Pentachlorophenol & Fluorene \\
\hline 2,4,6-trichlorophenol & Anthracene & Chrysene \\
\hline 2-chloronaphthalene & Fluoranthene & Benzo[k]fluoranthene \\
\hline Acenaphthene & 3,3'-dichlorobenzidine & Indeno[1,2,3-cd]pyrene \\
\hline Benzo[g;hi]perylene & Acenaphthylene & 4-chlorophenyl-phenylethe1 \\
\hline
\end{tabular}

Organochlorine pesticides (OCPs)

\begin{tabular}{|l|l|l|}
\hline Alpha BHC & Endosulfan II & Dieldrin \\
\hline Beta BHC & Endrin aldehyde & p,p'-DDD \\
\hline Delta BHC & Methoxychlor & p,p'-DDT \\
\hline Heptachlor epoxide & Gamma BHC-lindane & Endosulfan sulfate \\
\hline Alpha chlordane & Heptachlor & Endrin ketone \\
\hline p,p'-DDE & Gamma chlordane & Aldrin \\
\hline Endrin & Endosulfan I & \\
\hline
\end{tabular}


Organophosphorus pesticides (OPPs)

\begin{tabular}{|l|l|l|}
\hline Dichlorvos & Fenthion & Disulfoton \\
\hline Demeton O\&S & Tetrachlorvinphos & Dimethoate \\
\hline TEPP & Fensulfothion & Chlorpyrifos \\
\hline Sulfotep & Azinfos methyl & Parathion ethyl \\
\hline Diazinon & Mevinphos & Tokuthion \\
\hline Monocrotophos & Ethoprop & Bolstar \\
\hline Ronnel & Phorate & EPN \\
\hline Parathion methyl & Naled & Coumaphos \\
\hline
\end{tabular}

Chlorinated herbicides

\begin{tabular}{|l|l|l|}
\hline $2,4-\mathrm{D}$ & Dichloroprop & Dicamba \\
\hline $2,4,5-\mathrm{T}$ & $2,4-\mathrm{DB}$ & Dinoseb \\
\hline Dalapon & $2,4,5-\mathrm{TP}$ & \\
\hline
\end{tabular}

PCBs

\begin{tabular}{|l|l|l|}
\hline PCB 28 & PCB 101 & PCB 153 \\
\hline PCB 52 & PCB 138 & PCB 180 \\
\hline
\end{tabular}

as recommended in EPA method $3545 / 1 /$, corresponds to the class of compound to be extracted. For example, for extraction of BNA's and OPP's from solid matrices use dichloromethane/ acetone $(1: 1, v / v)$; OCPs require acetone / hexane $(1: 1, \mathrm{v} / \mathrm{v})$; PCBs require hexane / acetone $(1: 1, \mathrm{v} / \mathrm{v})$; and, chlorinated herbicides require acetone / dichloromethane/ phosphoric acid solution $(250: 125: 15, \mathrm{v} / \mathrm{v} / \mathrm{v})$. The term solid matrices normally refers to sewage sludge, soil, clays and (marine/river) sediment (although solid biological matrices also includes such samples as oyster tissue).

To demonstrate equivalency of PFE to Soxhlet (EPA Method 3540), automated Soxhlet (EPA Method 3541) and a solvent shake method (EPA Method 8150A) all the compounds (Table 1) were extracted at either two or three different concentration levels from three matrices (clay, loam and sand) 12/.The compound concentrations were as follows: BNA's, 250, 2500 and $12500 \mu \mathrm{g} / \mathrm{kg}$; OCP's, 5, 50 and $250 \mu \mathrm{g} / \mathrm{kg}$; OPP's, 250 and $2500 \mu \mathrm{g} / \mathrm{kg}$; and 
chlorinated herbicides, $50-500$ and $500-5000 \mu \mathrm{g} / \mathrm{kg}$. The results, based on seven replicates by each technique, were summarised as follows: BNA's, $99.2 \%$ average relative recovery for all compounds at all concentrations and from all matrices (12.8\% RSD for ASE, 13.9\% RSD for Automated Soxhlet); OCP's, $97.3 \%$ average relative recovery for all compounds at all concentrations and from all matrices (8.3\% RSD for ASE, 8.7\% RSD for Automated Soxhlet); OPP's, 98.6\% average relative recovery for all compounds at all concentrations and from all matrices $9.3 \%$ RSD for ASE, 8.4\% RSD for Automated Soxhlet); and, herbicides, $112.9 \%$ average relative recovery for all compounds at all concentrations and from all matrices (24.5 $\%$ RSD for ASE, 31.5\% RSD for Shake method). In each case ASE was operated as follows: temperature, $100^{\circ} \mathrm{C}$; pressure, $2000 \mathrm{psi}$; and a $5 \mathrm{~min}$ heat up time followed by $5 \mathrm{~min}$ static. The comparison techniques conditions were altered as per compound class to be extracted (Table 2). It was concluded that the "method is applicable to virtually all of the extractable organics on the RCRA target analyte list" /3/. [NOTE: RCRA - Resource Conservation Recovery Act].

Table 2

Equivalency testing of PFE: Use of alternative techniques

\begin{tabular}{|c|c|c|c|c|}
\hline & $\begin{array}{c}\text { Automated } \\
\text { Soxhlet }\end{array}$ & $\begin{array}{c}\text { Automated } \\
\text { Soxhlet }\end{array}$ & Soxhlet & Shake \\
\hline & BNA's & OCP s & OPP's & $\begin{array}{c}\text { Chlorinated } \\
\text { herbicides }\end{array}$ \\
\hline Sample size & 10 or $14 \mathrm{~g}$ & $10 \mathrm{~g}$ & $10 \mathrm{~g}$ & $10 \mathrm{~g}$ \\
\hline Solvent & $\begin{array}{c}\text { DCM/acetone } \\
(1: 1), 50 \mathrm{ml}\end{array}$ & $\begin{array}{c}\text { hexane/acetone } \\
(1: 1), 50 \mathrm{ml}\end{array}$ & $\mathrm{DCM}, 250 \mathrm{ml}$ & $\begin{array}{l}\text { Acetone, } 60 \mathrm{ml} \text {, } \\
\text { diethyl ether, } \\
240 \mathrm{ml} \text { after } \\
\text { soil, } \mathrm{pH}=2\end{array}$ \\
\hline Temperature & $140^{\circ} \mathrm{C}$ on heater & $140^{\circ} \mathrm{C}$ on heater & $40^{\circ} \mathrm{C}$ & $\begin{array}{c}\text { Room } \\
\text { temperature }\end{array}$ \\
\hline Pressure & Atmospheric & Atmospheric & Atmospheric & Atmospheric \\
\hline Time & $\begin{array}{c}60 \text { min boil; } 60 \\
\text { min rinse }\end{array}$ & $\begin{array}{c}60 \text { min boil; } 60 \\
\text { min rinse }\end{array}$ & 18 hour reflux & $\begin{array}{l}2 \text { hours shaking } \\
\text { plus decanting }\end{array}$ \\
\hline Analysis & GC-MSD & GC-ECD & GC-NPD & GC-ECD \\
\hline
\end{tabular}




\section{THEORETICAL CONSIDERATIONS}

Liquid solvents at elevated temperatures and pressures should provide enhanced extraction capabilities compared to their use at or near room temperature and atmospheric pressure for two main reasons /4/: (1) solubility and mass transfer effects, and (2) disruption of surface equilibria.

\section{Solubility and mass transfer effects}

Three factors are considered important:

- higher temperature increases the capacity of solvents to solubilise analytes. This is illustrated in Figure 1 which shows the effect of temperature on the solubility of glycine in water (the solubility of glycine increases approximately 5 -fold over the temperature range $0-100^{\circ} \mathrm{C}$ ) $/ 5 /$.

- faster diffusion rates occur as a result of increased temperature.

- improved mass transfer and hence increased extraction rates occur when fresh solvent is introduced i.e. the concentration gradient is greater between the fresh solvent and the surface of the sample matrix.

\section{Disruption of surface equilibria}

As both temperature and pressure are important both are discussed separately.

\section{Temperature effects:}

- increased temperatures can disrupt the strong solute-matrix interactions caused by van der Waal's forces, hydrogen bonding, and dipole attractions of the solute molecules and active sites on the matrix.

- a decrease in viscosity and surface tension of solvents occurs at higher temperature thus allowing improved penetration of the matrix, and hence improved extraction. An example, of the decreasing viscosity of toluene with respect to temperature is shown in Figure 2 /6/, while Figure 3 shows the decreasing surface tension of water as temperature increases $/ 6 /$.

\section{Pressure effects:}

- The utilisation of elevated pressures allows solvents to remain liquified above their boiling points. 


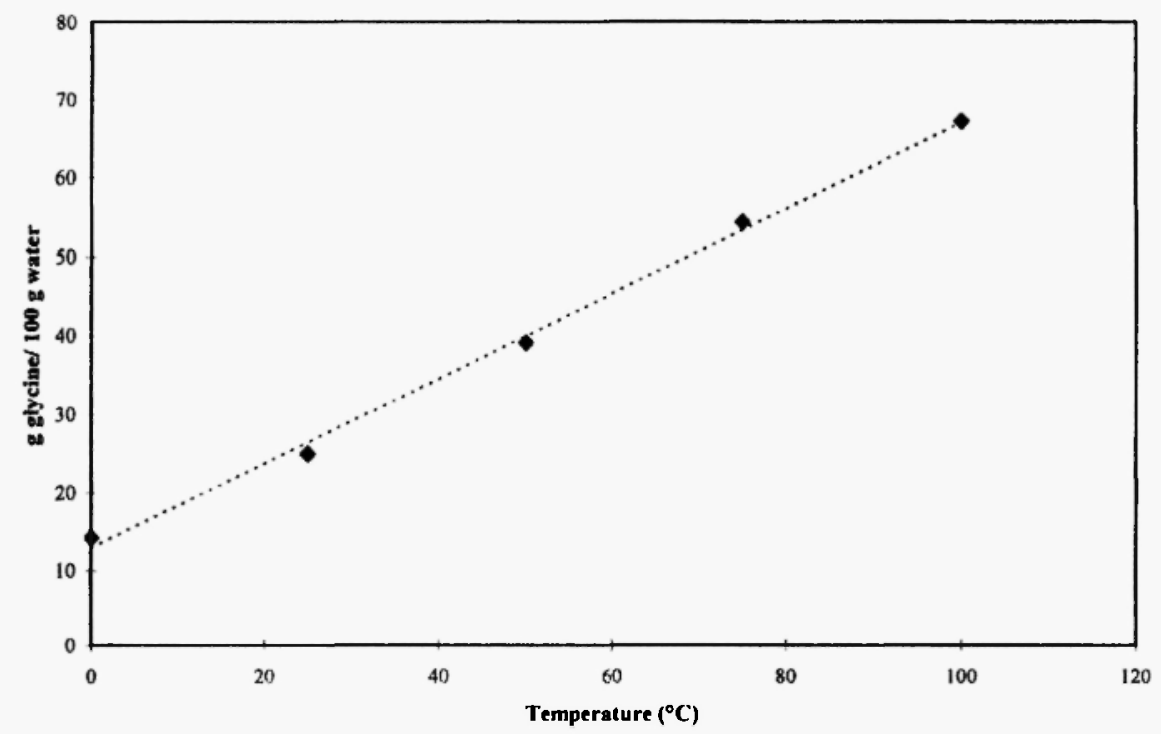

Fig. 1: Effect of temperature on the solubility of glycine in water

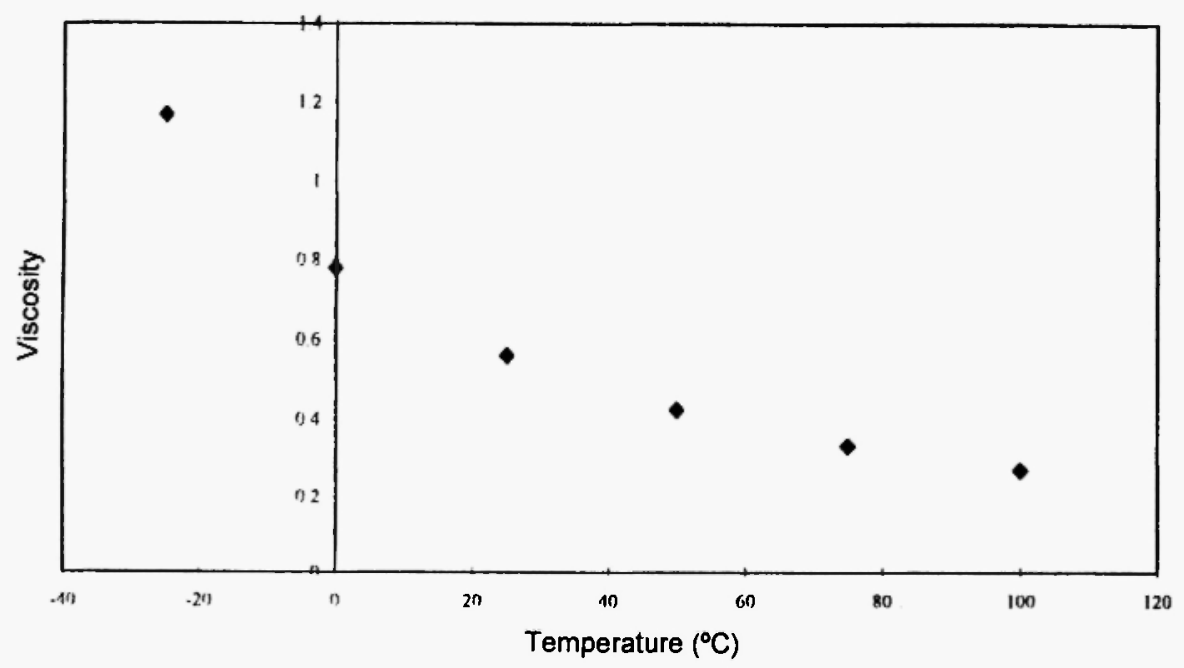

Fig. 2: Effect of temperature on the viscosity of toluene 


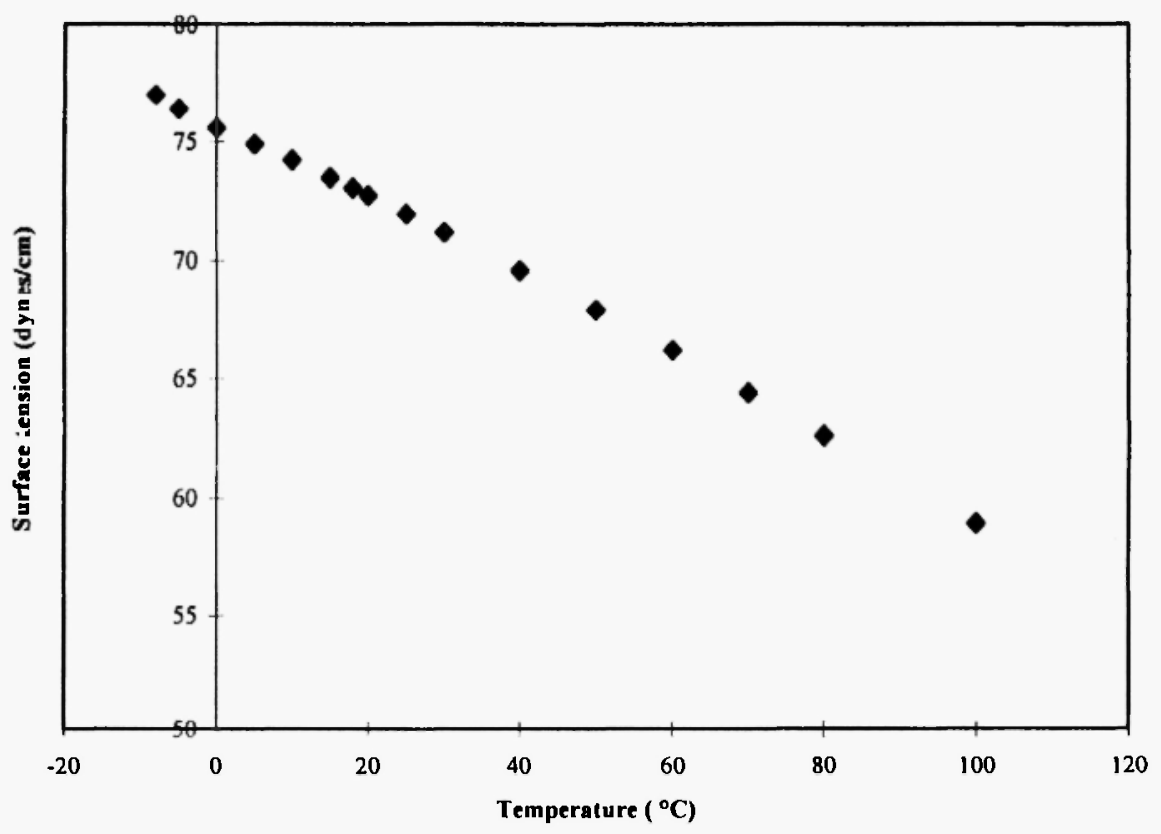

Fig. 3: Effect of temperature on the surface tension of water

- Extraction from within the matrix is possible, as the pressure allows the solvent to penetrate the sample matrix.

\section{INSTRUMENTATION}

The commercial PFE instrument is a fully automated sequential extraction system. A schematic diagram of a system is shown in figure 4 . The system (ASE 200) can operate with up to 24 sample containing extraction vessels and up to 26 collection vials plus an additional 4 vial positions for rinse/waste collection. Five sample extraction vessel sizes are available: 1, 5, 11,22 and $33 \mathrm{ml}$. The sample vessel has removable end caps that allow for ease of cleaning and sample filling. Each sample vessel is fitted with two finger-tight caps with compression seals for high pressure closure. To fill a sample vessel, one end cap is introduced and screwed on to finger-tightness. Then, a filter paper (Whatman, grade $\bar{D} 28,1.98 \mathrm{~cm}$ diameter) is introduced into the sample vessel, followed by the sample itself. Samples should normally be air-dried or mixed with a suitable drying agent e.g. anhydrous 


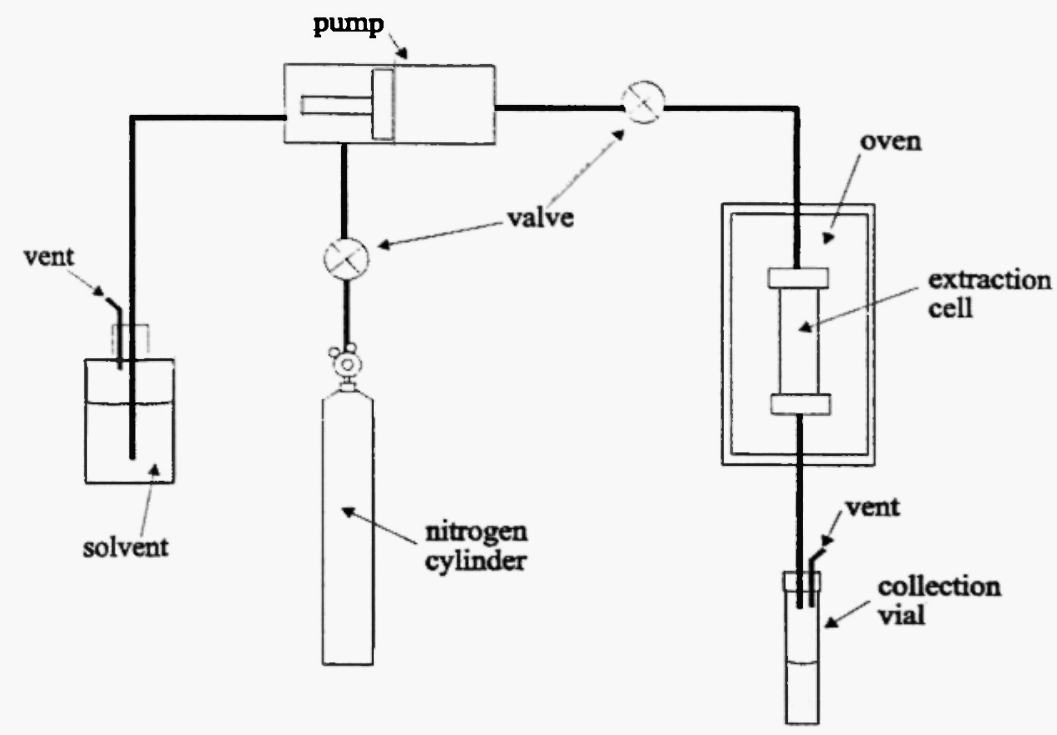

Fig. 4: Schematic diagram of a pressurised fluid extraction system

sodium sulfate, and ground to $100-200$ mesh $(150 \mu \mathrm{m}$ to $75 \mu \mathrm{m})$. Then, the other end cap is screwed on to finger-tightness and the sample vessel placed in the carousel. Through computer control the carousel introduces selected extraction vessels consecutively. An auto-seal actuator places the extraction vessel into the system and then returns the vessel to the carousel after extraction. The system is operated as follows: the sample cell, positioned vertically, is filled from top to bottom with the selected solvent or solvent mixture from a pump (capable of operating at up to $70 \mathrm{ml} \mathrm{min}$ ) ) and then heated to a designated temperature $\left(40-200^{\circ} \mathrm{C}\right)$ and pressure $(6.9-20.7$ $\mathrm{MPa}$ or $1000-3000 \mathrm{psi}$ ). These operating conditions are maintained for a pre-specified time using static valves. After, the appropriate time (typically 5 mins) the static valves are released and a few ml of clean solvent (or solvent mixture) is passed through the sample cell to exclude the existing solvent(s) and extracted analytes. This flush volume is normally 0.6 times the cell volume. This rinsing is enhanced by the passage of $\mathrm{N}_{2}$ gas ( $45 \mathrm{~s}$ at $150 \mathrm{psi}$ ) to purge both the sample cell and the stainless steel transfer lines. After gas purging, all extracted analytes and solvent(s) are passed through $30 \mathrm{~cm}$ of stainless steel tubing that punctures a septa (solvent resistant; coated with teflon on the solvent side) located on top of the glass collection vials (40 or $60 \mathrm{ml}$ capacity). If required, multiple extractions can be performed per 

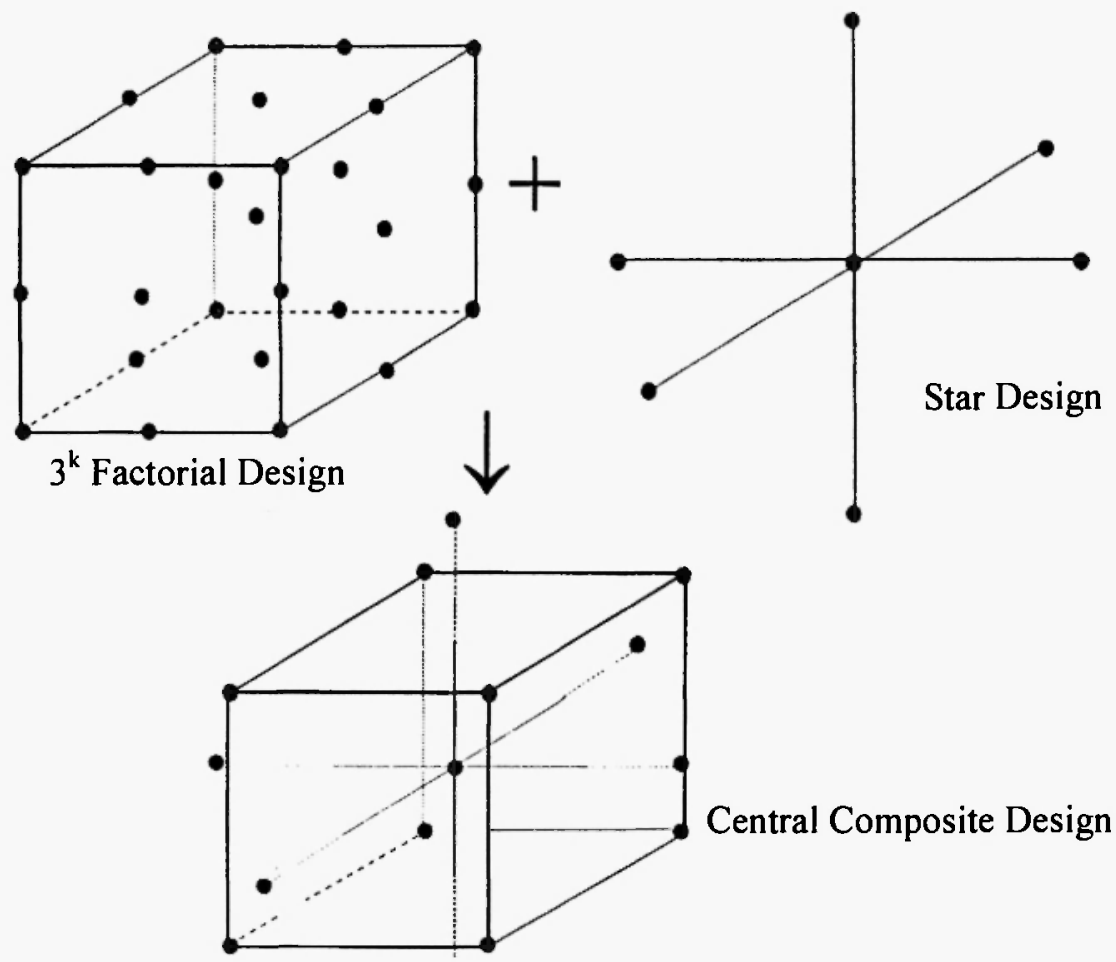

Fig. 5: Central composite design

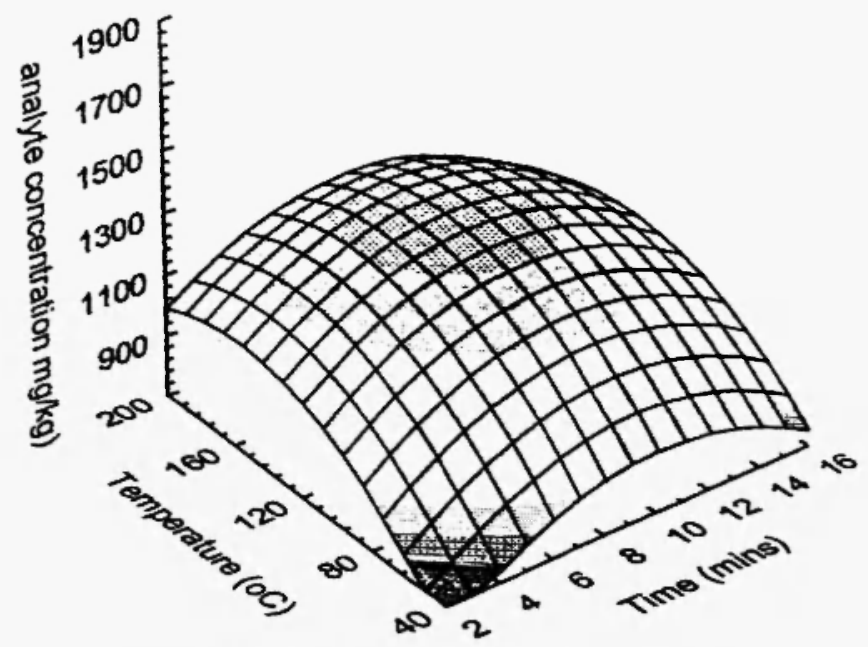

Fig. 6: Typical response surface profile 
extraction vessel. The arrival and level of solvent in the collection vial is monitored using an IR sensor. In the event of system failure, an automatic shut off procedure is instigated.

In addition to commercial systems, various groups have assembled their own systems $/ 7 \%$. Typically, this has involved the use of a syringe pump, stainless steel extraction cell, an oven, collection vial, a supply of nitrogen gas, stainless steel tubing and strategic positioning of various (Rheodyne) valves. The use of 'home-made' instruments, and hence loss of automation, has not detracted from the results obtained. Alternatively, converted SFE systems /8-10/ have been used for PFE. Again appropriate results have been obtained.

\section{METHOD DEVELOPMENT}

\section{Optimization of PFE extraction conditions}

Central composite design (CCD) is an efficient method of optimizing PFE extraction conditions. In order to accomplish this it is important to use 'real' samples, i.e. aged contaminated samples are necessary. If a similar matrix to that of interest can be selected for evaluation this is also beneficial. A central composite design (CCD) is the combination of a two-level full factorial design superimposed on a star design. The centres of the two designs coincide (Figure 5) /11/. The CCD takes the form of a cube with star points located in the centre of each face (Figure 5).11 The main variables for PFE are pressure, temperature and time. In order to evaluate these three variables it is necessary to select operational (safe working) limits prior to commencement. Typically, the following limits can be used: pressure, 1000 and 2400 psi; temperature, 40 and $200{ }^{\circ} \mathrm{C}$; and, time, 2 and 16 minutes. If this is done, the $\mathrm{CCD}$ requires sixteen experiments to be performed. Data evaluation can be achieved using multilinear regression which shows the relationship between the amount of analyte extracted (response) and the operating variables. The results of the regression analysis can be used to plot a response surface (Figure 6). The response surface can be utilised to select ideal operating conditions. Saim et al. /12/ used this approach to determine the optimum extraction conditions for polycyclic aromatic hydrocarbons (PAHs) from highly, contaminated soil. However, they found that none of the parameters investigated had any significant effect on the recovery of PAHs. 
A different approach used by Schantz et al. /13/ involved keeping the over. temperature constant $\left(100^{\circ} \mathrm{C}\right)$ and varying the pressure between 1000 and 2200 psi. To optimise the extraction temperature, constant pressure was established, whilst the temperature was varied between 50 and $150^{\circ} \mathrm{C}$. The optimum conditions for PAHs, PCBs and chlorinated pesticides were established as $100^{\circ} \mathrm{C}$ and $2000 \mathrm{psi}$. In contrast Obana et al. $/ 14 /$ used a 'one at a time' approach for the extraction of acephate and methamidophos from orange juice. They determined that an increase in pressure $(1500,2000$ and $2500)$ improved the extraction efficiency $(9.5,13.3$ and $15.0 \%$ recovery for methamidophos; $16.0,20.0$ and $22.2 \%$ recovery for acephate), but time and temperature (extraction time, 5, 10, 15 mins; and temperature, 50, 100, 150 ${ }^{\circ} \mathrm{C}$ ) had no effect on this system.

\section{Optimization of Static / Flush Cycles}

There is a fundamental difference between Soxhlet extraction and PFE. In Soxhlet extraction, fresh solvent is cycled through the sample at the rate of approximately 4 cycles per hour. In PFE this is not the case. In order to mimic the cycling of solvent, the PFE can perform up to three static-flush cycles in any single extraction, allowing the PFE to mimic the action of Soxhlet extraction. Popp et al. /15/ have extracted chlorinated pesticides from soil. They investigated the number of static flush cycles require for quantitative extraction (Figure 7). They concluded that two static flush cycles were required for quantitative extraction work. This finding is in contrast to the EPA method (method 3545)1 which suggests only one 5 minute static extraction cycle. Popp et al. $/ 15 /$ compared the EPA method with a static extraction time of 10 and 15 minutes, as well as two static steps of 5 minutes. They concluded that there was no significant difference between the 10 and 15 minutes extraction steps, but two successive 5 minute cycles extracted more than either of the longer cycles. Bjorklund et al. /16/ have also investigated this approach. In their work PCBs were extracted from a certified reference material (harbour sediment, CRM 536). They also observed that one static step is not always able to quantitatively extract the analyte from a matrix (Figure 8). Initial investigations showed that PCBs were present in the second extract. Further work (also shown in Figure 8) indicated that two solvent cycles gave higher extraction efficiencies that two separate extractions. 


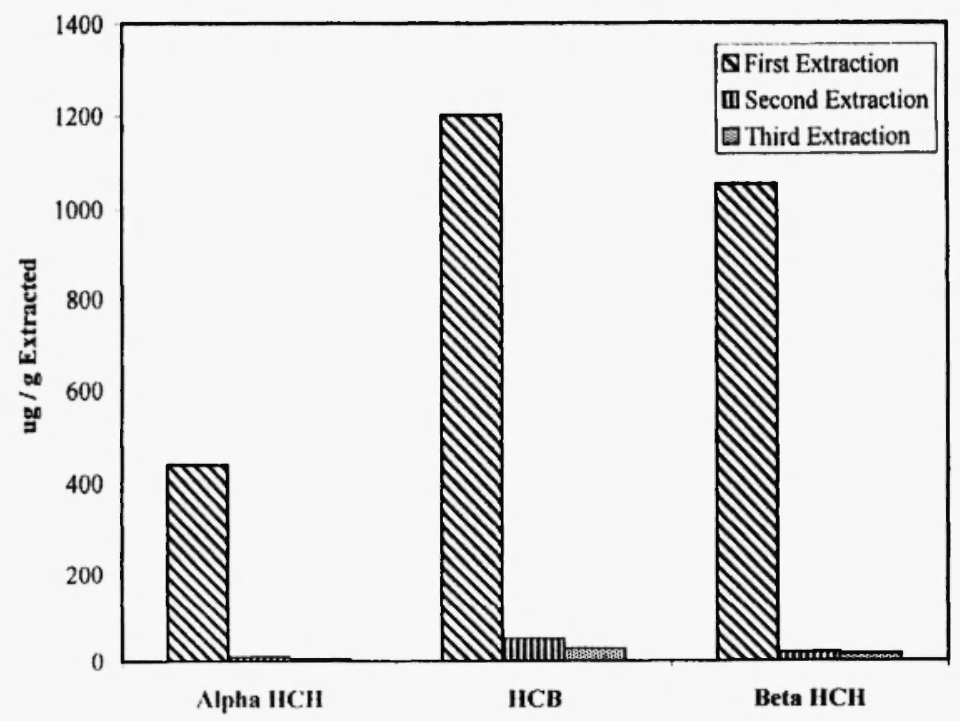

Fig. 7: ASE cycle study

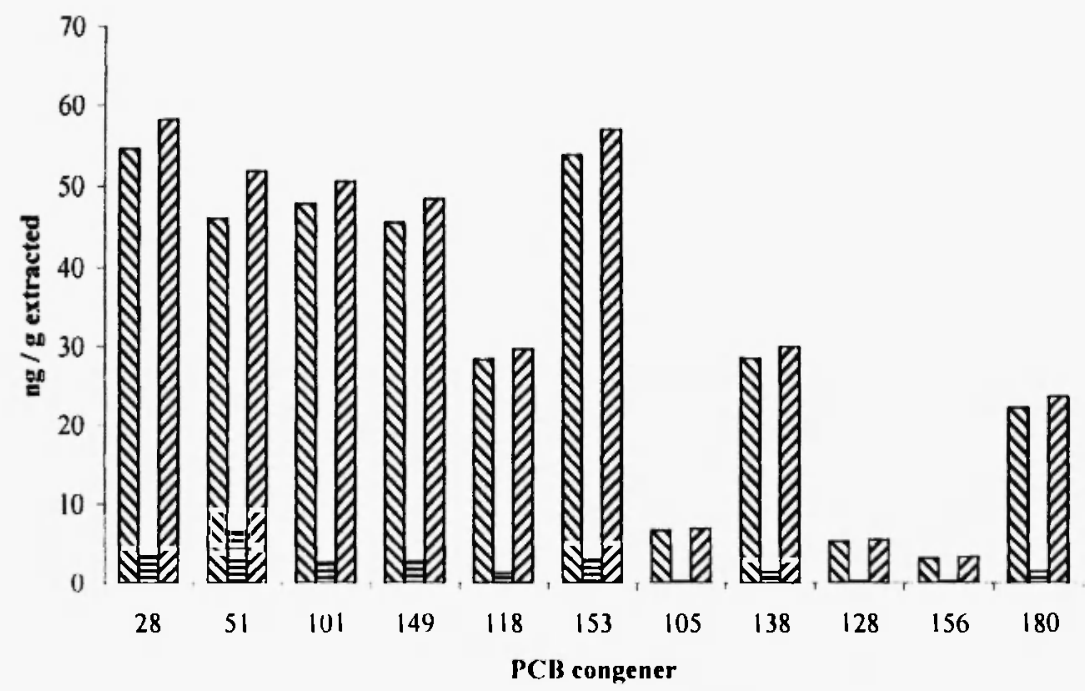

Fig. 8: Effect of cycles on PCB extraction 


\section{Optimisation of PFE Extraction Solvent}

Optimisation of solvent for an extraction procedure is very often time consuming, and many traditional extraction techniques, such as Soxhlet extraction, require large volumes of organic solvent. The current trend is to reduce the consumption of organic solvents (particularly chlorinated organic solvents) used in the laboratory, as these have detrimental environmental effects if disposed of incorrectly. The automated nature of the PFE technique, together with its minimal use of organic solvent, allows an investigation to be easily made. Usually, comparison of several solvent systems is necessary to fully optimize the extraction process. For example, Popp et al. $/ 15 /$ have used three different solvent systems, namely toluene, DCM:acetone, and acetone:hexane (solvent mixtures were used in the volume ratio of $1: 1$ ) for the extraction of spiked soil contaminated with DDT and its metabolites, DDD and DDE. They determined that acetone:hexane $(1: 1, v / v)$ was the optimum solvent for the extraction (Figure 9).

Obana and co workers /14/ have compared six solvent systems (ethyl acetate, acetonitrile, ethyl acetate:acetone, DCM:acetone, toluene:acetone, and, cyclohexane:acetone) for the extraction of organophosphorus pesticides (acephate and methamidophos) from orange juice (Figure 10). They determined that ethyl acetate gave the highest recoveries of the two OPPs. Poster et al. /17/ compared three solvent systems for the extraction of PCBs and chlorinated pesticides from a standard reference material, an urban dust (SRM 1649). The solvent systems used were acetonitrile, DCM and hexane:acetone $1: 1(\mathrm{v} / \mathrm{v})$. The authors indicated that differences between the PCB congeners and chlorinated solvents using three different solvent systems were typically $<5 \%$. No noticeable differences were observed between PFE and Soxhlet extraction.

An alternative approach to solvent optimization is to predict the solvent required that would give quantitative extraction of the analyte. Recently, a model based on the Hildebrand solubility parameter has been developed /18/. The solubility parameter, $\delta$, is defined as the square root of the cohesive energy density or

$$
\delta=\left(\Delta \mathrm{E}_{\mathrm{v}} / \mathrm{V}\right)^{1 / 2}
$$

where

$\Delta E_{v}=$ the energy of vaporisation at a given temperature

$\mathrm{V}=$ molar volume of the molecule $/ 19 /$. 


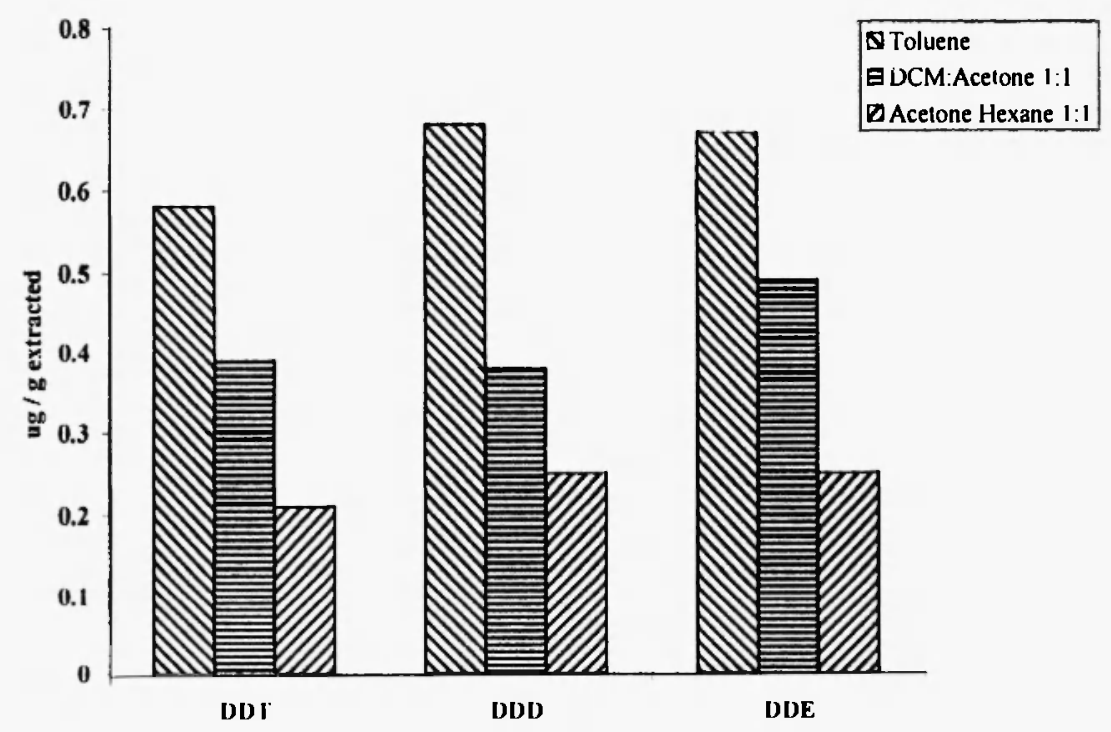

Fig. 9: Comparison of solvent for extraction

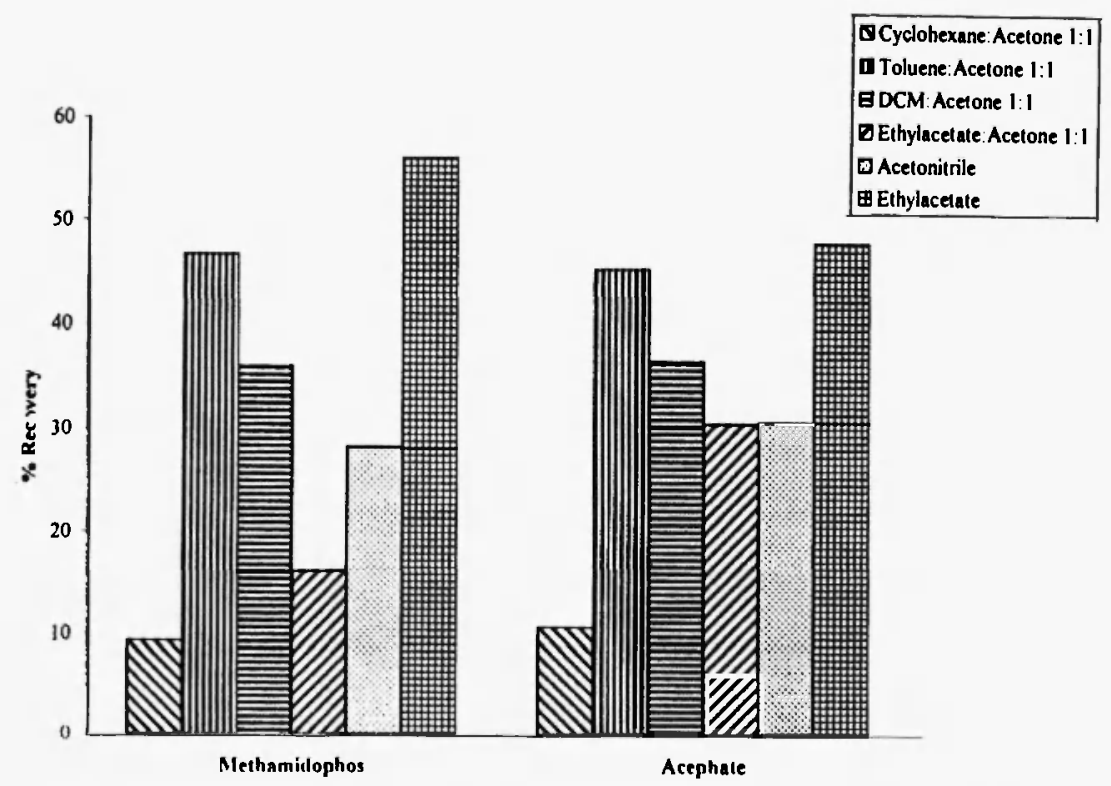

Fig. 10: Comparison of solvent systems for the extraction of OCPS 
The solubility parameter is used as a measure of the solubility of compounds in various solvents.

However, calculations of this sort require knowledge of the heat of vaporisation at various temperatures as well as the molar volume of the substance. However, these values are not widely available for a wide range of molecules of environmental interest. Hansen $/ 20 /$ has taken this work further and assumes the total cohesive energy is a linear addition of three components: $\delta_{\mathrm{h}}$, hydrogen bonding ability contribution; $\delta_{\mathrm{d}}$, dispersion co-efficient contribution; and, $\delta_{\mathrm{p}}$, polarity contribution. They are linked by the following equation:

$$
\delta_{\mathrm{t}}^{2}=\delta_{\mathrm{h}}^{2}+\delta_{\mathrm{p}}^{2}+\delta_{\mathrm{d}}^{2}
$$

Calculation of each component is achieved via group contribution data in the literature. Thermodynamic data to develop equations for the calculation of the individual parameters of the total solubility parameter are available $/ 21,22 /$. The method used was addition of group contributions. Tables of data were set up containing each group's contribution to polarity, dispersion and hydrogen bonding $\left(F_{p}, F_{d}\right.$, and $U_{h}$, respectively). Using the following equations $(3-6) \delta_{\mathrm{p}}, \delta_{\mathrm{h}}$, and $\delta_{\lambda}$ can be calculated.

$$
\begin{aligned}
& \delta_{d}=\left({ }_{z} \sum^{z} F_{d}\right) / V \\
& \delta_{p}=\left({ }_{z} \sum^{z} F_{p}\right) / V^{*} \\
& \delta_{p}=\left({ }_{z} \sum^{z} F_{p}{ }^{2}\right)^{1 / 2} / V \\
& \delta_{h}=\left(\left({ }_{z} \sum^{z} U_{h}\right) / V\right)^{1 / 2}
\end{aligned}
$$

* for molecules with more than 1 polar group present, then equation 5 must be used instead of equation 4 , to take into account the interactions between the polar groups $/ 22 /$.

A sample calculation of the individual components of the solubility parameter for a solvent (methanol) is shown in Table 3. The values for the group contributions were taken from reference 22 .

Fractional parameters of the Hildebrand solubility parameter can be calculated using equations $3-6$ and plotted on a triangular graph in order to 
Table 3

Calculation of individual group contributions for Methanol

\begin{tabular}{|c|c|c|c|c|}
\hline Group & \begin{tabular}{c|} 
Group \\
contribution to \\
dispersion $\left(F_{\mathrm{d}}\right)$ \\
$\mathrm{J}^{1 / 2} \mathrm{~cm}^{3 / 2} \mathrm{~mol}^{1 /}$
\end{tabular} & $\begin{array}{c}\text { Group } \\
\text { contribution } \\
\text { to polarity } \\
\left(F_{p}\right) \\
J^{1 / 2} \mathrm{~cm}^{2} \text { mol }^{1}\end{array}$ & $\begin{array}{c}\text { Group } \\
\text { contribution to } \\
\text { hydrogen } \\
\text { bonding } \\
\left(\mathrm{U}_{\mathrm{h}}\right) \\
\mathrm{J} \mathrm{mol}^{-1} \\
\end{array}$ & $\begin{array}{c}\text { Molar } \\
\text { volume } \\
\text { (V) } \\
\mathrm{cm}^{3} \text { mor }^{-1}\end{array}$ \\
\hline $\mathrm{CH}_{3}$ & 420 & 0 & 0 & 33.5 \\
\hline $\mathrm{OH}$ & 210 & 500 & 20000 & 10.0 \\
\hline Total & 630 & 500 & 20000 & 43.5 \\
\hline
\end{tabular}

give a visual representation of the extent of contribution from the three components (polarity, dispersion and hydrogen bonding). A visual representation between the three components is via a triangular graph using fractional parameters (Figure 11). The triangle can be used to predict the best solvent for dissolving a compound. The optimum solvent should be in the same position as the target analyte. This thinking can be applied to extraction techniques. To quantitatively extract an analyte from a matrix, the solvent should have similar properties to the compound, i.e. non-polar solvents are better at extracting non-polar analytes. Using this approach, an informed selection of the most suitable solvent for a particular analyte can then be made.

\section{Effect of particle size}

Scant literature exists on the influence of particle size on the recovery of analytes using PFE. Bjorkland $e t$ al. $/ 16 /$ have extracted marine sediment contaminated with PCBs. As part of this study they included a brief investigation as to the relationship between analyte recovery and particle size. Perhaps unsurprisingly, they found that smaller particle size results in increased extraction efficiency. Figure 12 compares the results of the extraction of PCBs from harbour sediment (CRM 536) with a particle size of $<15 \mu \mathrm{m}$ and a particle size between 75 and $1000 \mu \mathrm{m}$. The authors noted that greater extraction efficiency (versus the certified values) occurred with the smaller particle size $(<15 \mu \mathrm{m})$. However, it was noted that, irrespective of particle size, both sediments yielded greater amounts of PCB's than the stated certified value. 


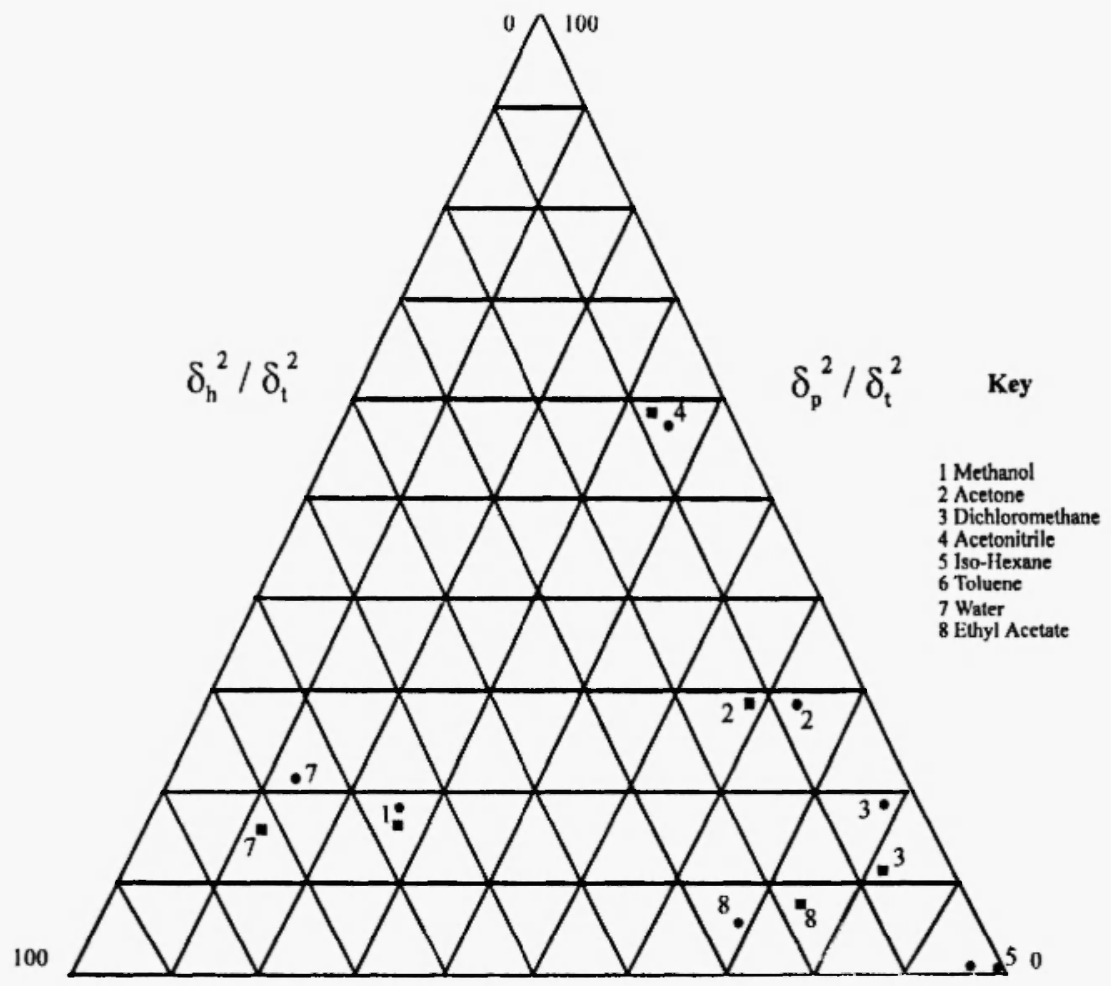

Fig. 11: Fractional parameters for selected solvents

\section{Proposal for PFE method development}

A suggestion for a procedure for method development for PFE is given below based on the scientific literature, as discussed above, and our own experience in the use of a commercial PFE instrument since 1996/23/:

1. Determine the identity of the analyte(s).

2. Sample preparation.

Air dry sample for 24 hours.

Grind sample to a small particle size $(<15 \mu \mathrm{m})$, mix well to ensure homogeneity.

Mix sample with a dispersing agent prior to extraction. 


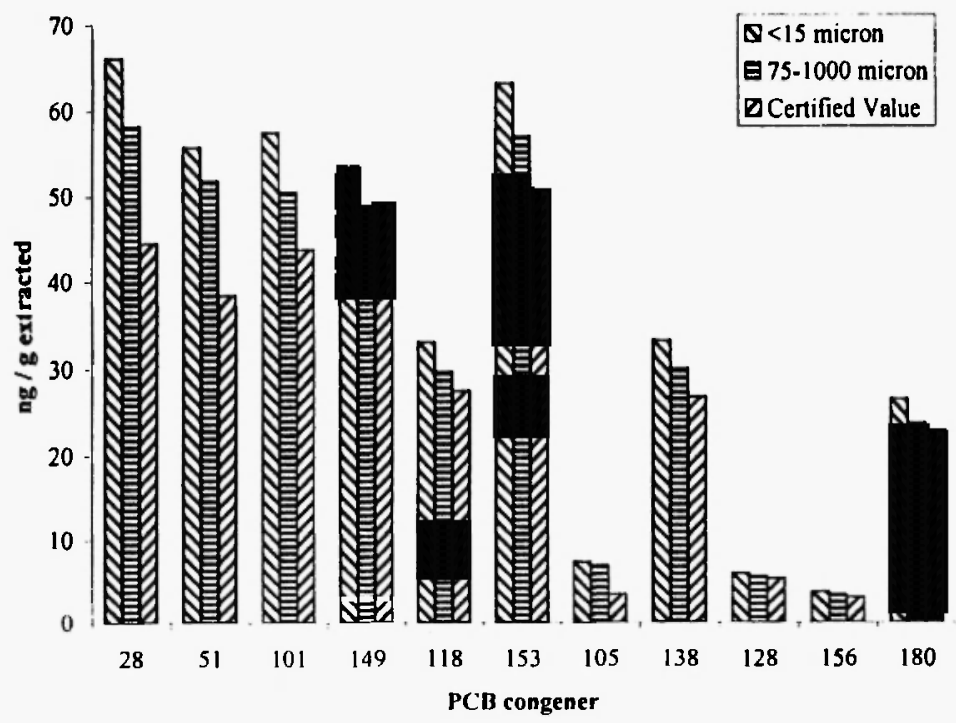

Fig. 12: Effect of particle size on $\mathrm{PCB}$ extraction

3. Optimize operating variables (time, temperature and pressure) via one of the following methods

- Central composite design, or other experimental design matrix e.g. factorial design.

- Simplex design

4. Investigate solvent selection via a prediction model, experience or trial and error.

5. Investigate the influence on analyte recovery from a 'real' sample of static flush cycles.

Once all the extraction parameters have been optimized, recovery experiments from spiked inert matrices are required to assess the proposed method work-up procedure. Caution should be exercised at this stage, as spiking rarely reflects what happens in 'real' samples. Two methods of spiking are widely used. The first, called spot spiking, is where the analyte is introduced to the matrix in a small volume of solvent (typically $\mu \mathrm{l}$ ). The solvent is then allowed to evaporate and the matrix is extracted. Several studies /24-26/ have shown that this type of spiking gives quantitative recoveries (not surprisingly), as the analyte does not have sufficient time to interact with the matrix and (potentially) become more resistant to its 
removal. The second, more realistic approach is called slurry spiking. In this case, analytes are introduced on to the matrix in a large volume of solvent. The solvent is allowed to evaporate and the matrix is left for a significant length of time (ideal minimum 1 month) before extraction. This allows the analyte(s) time to interact with the matrix. This former approach has been investigated by Dean et al. $/ 7 /$ and Frost et al. $127 /$ who found that lower recoveries were obtained from aged samples.

To fully assess a new technique, a range of aged, contaminated samples should be extracted and compared with alternative extraction techniques, such as Soxhlet extraction.

\section{APPLICATIONS OF PFE}

\section{Phenols}

Phenolic compounds are widely used in the chemical industry for the manufacture of polymers, textiles, resins, dyes, petroleum refining, pulp processing and coal coking and as pesticides and herbicides. Some of these toxic aryl alcohols are included in the list of priority pollutants of the US Environmental Protection Agency, as well as in some European regulations 128/.

Dean et al. $/ 7 /$ optimized the accelerated solvent extraction of seven phenols (phenol, 2,4-dichlorophenol, 4-nitrophenol, 4-chloro-3- methylphenol, 2-metholphenol, 2-nitrophenol and 2,4-dimethylphenol) from a slurry spiked soil sample (3.8\% carbon, $3.4 \%$ water and $\mathrm{pH}$ of 6.1 ) using a central composite design and compared it with shake-flask extraction. None of the variables studied were found to be significant within the limits investigated (pressure, 4-20 MPa; temperature, $30-70{ }^{\circ} \mathrm{C}$; and extraction time 5-25 min) except for 2-methylphenol. Recoveries obtained by both PFE and shake-flask extraction were good and comparable for all the phenols studied (Figure 13) except for 2,4-dichlorophenol which was hardly extracted by PFE ( $24.5 \%$ recovery) and not recovered at all by shake-flask extraction.

\section{Polycyclic aromatic hydrocarbons}

Polycyclic aromatic hydrocarbons (PAHs) are an important group of organic pollutants which exhibit carcinogenic and/or mutagenic properties and are listed by the US EPA Environmental Protection Agency and the 


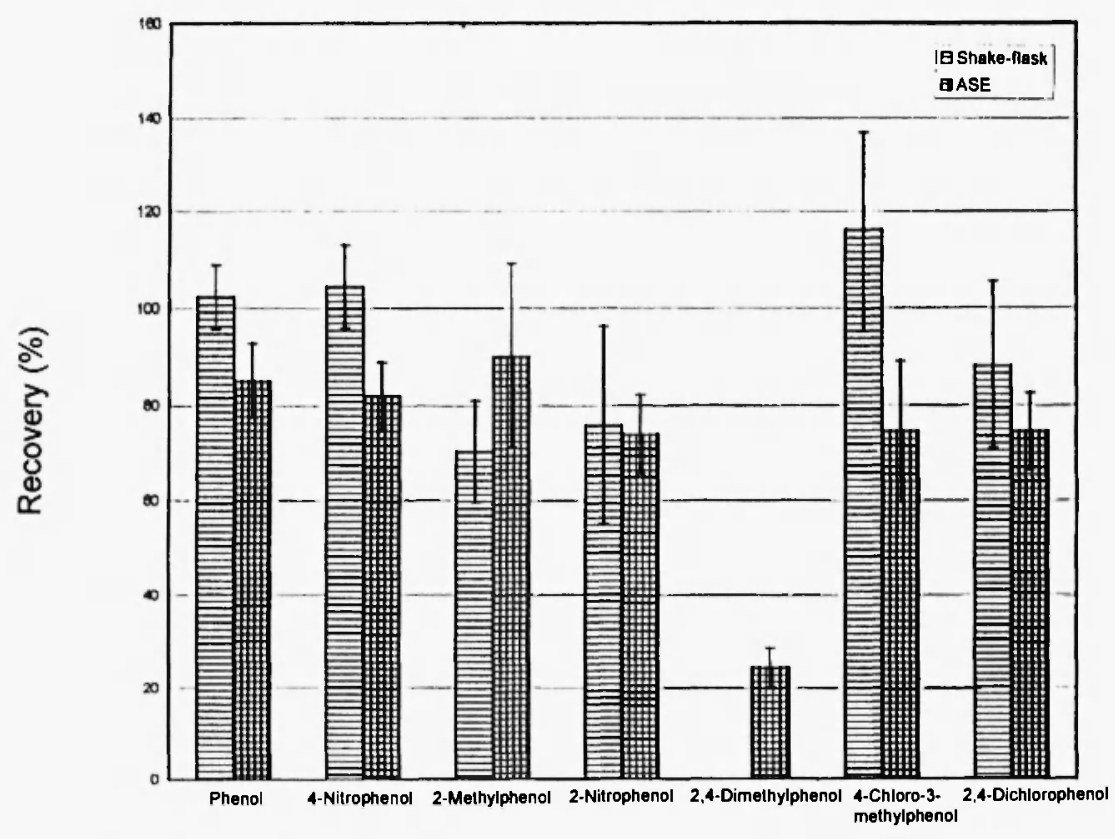

Fig. 13: Comparison of shake-flask and accelerated solvent extraction for phenols. Shake-flask: $10 \mathrm{ml}$ acetonitrile-water (40:60) for $10 \mathrm{~min}$; ASE: $100 \%$ acetonitrile.

European Community as priority pollutants $128 /$. They are produced by heating and power production, industrial producers, incineration and open burning, and vehicular transport $/ 28 /$ and thus enter the environment from a wide variety of sources and are present in all sectors of the environment (atmosphere, soil, water).

The influence of different variables (pressure, temperature, extraction time and extraction solvent) for the PFE of PAHs from a native contaminated soil with an organic carbon content of $10.2 \%$ was reported by Saim et al. 112/. From the results obtained from the central composite design, built to study the influence of pressure, temperature and extraction time, it could be concluded that none of them had a significant influence on the recovery within the ranges studied (pressure, $1000-2400 \mathrm{psi}$; temperature, $40-200{ }^{\circ} \mathrm{C}$; and extraction time, 2-16 mins). Different individual solvents (hexane, dichloromethane, acetone, methanol, and acetonitrile) and two solvent mixtures (dichloromethane + acetone and hexane + acetone, both as $1+1$ combinations) were tried as extraction solvents. Under standard operating 
conditions, as recommended in EPA method $3545 / 1 /$, i.e., temperature $100^{\circ} \mathrm{C}$, pressure $2000 \mathrm{psi}$, and an extraction time of $5 \mathrm{~min}$ with $5 \mathrm{~min}$ equilibration time, solvent, singly or in combination, had no effect on the recovery of PAHs, except hexane. The poor recoveries obtained for hexane were attributed to its lower polarity. Figure 14 shows the effect of solvent on the recovery of PAHs.

Heemken et al. /29/ extracted PAHs and alkanes from a reference marine sediment (HS-6, $3 \mathrm{wt} \%$ water content) and air-dried suspended particulate matter (SPM, $5.3 \mathrm{wt} \%$ water content) from the rivers Elbe and Weser by PFE, SFE, methanolic saponification and Soxhlet and found that the results were not significantly different. In the same work $/ 29 /$, the influence of water on extraction efficiency was studied using SPM samples containing $56 \mathrm{wt} \%$ water. It was noted that decreased recoveries were obtained. It was suggested that the diffusion of solvent into the matrix is impaired by the high water content. To be able to extract undried SPM without the time-consuming drying processes, it was recommended that a homogeneous mixture of SPM

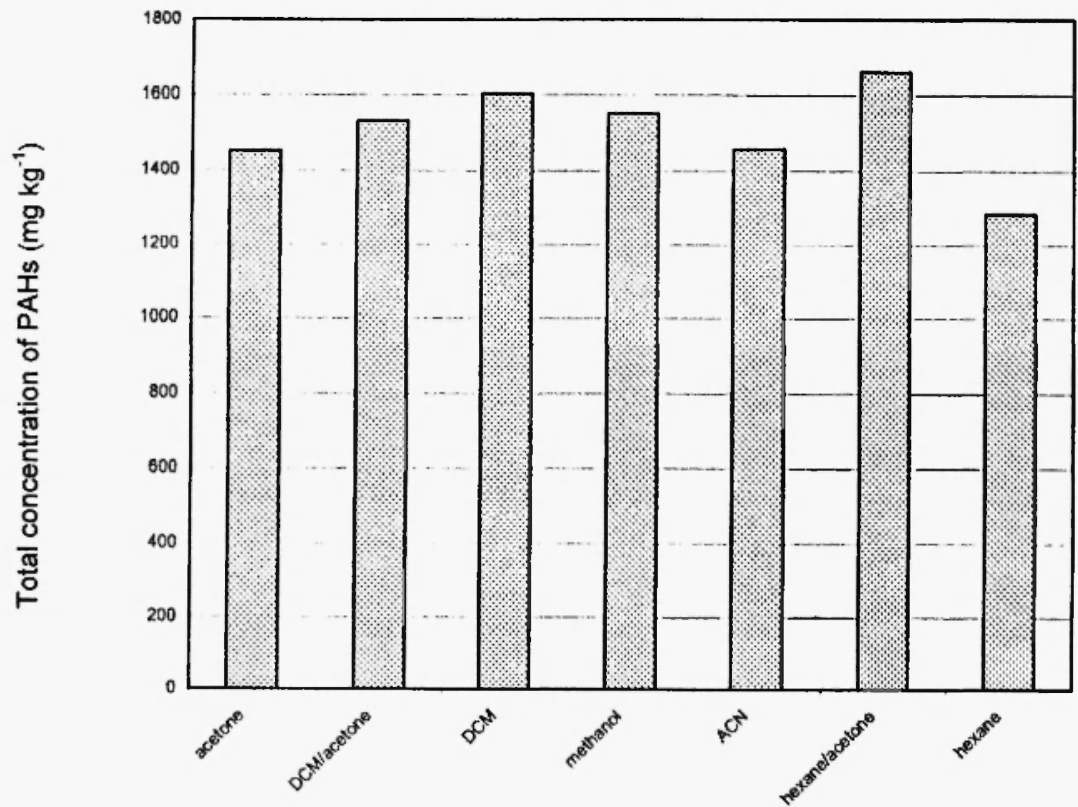

Fig. 14: Effect of solvent on the recovery of PAHs from a native contaminated soil. 
with $\sim 4 w t \%$ portions of anhydrous sodium sulfate was used. However, thi operator should be aware of the potential risk of sample contamination by the extra sample manipulation involved.

A comparison of PFE with Soxhlet extraction, pressurised and atmospheric microwave-assisted extraction and supercritical fluid extraction for the removal of PAHs from a native contaminated soil was done by Saim et al. $/ 34 /$. Figure 15 shows the recoveries obtained by the different extraction techniques. In all cases, with the exception of benzo[ $a$ ]anthracene by PFE, the results (Figure 15) gave extraction recoveries less than Soxhlet extraction. However, there are other points apart from recoveries which can be used to compare different techniques. In terms of organic extraction solvent usage, SFE is the most favourable; however, for speed of extraction MAE is better (12 samples in $\sim 20 \mathrm{~min}$ ); while the level of automation of the PFE system will allow the operator to complete alternative tasks in the laboratory. The adoption of these techniques as an alternative to Soxhlet extraction is anticipated $/ 23 /$.

The extraction of PAHs from an aged bituminous coal fly ash with a 15.5 wt $\%$ carbon content and 6-16 $\mu \mathrm{m}$ particle size was reported by Kenny et al. 135/. In this work, two different solvents for PFE were used (methylene chloride with or without a static step and toluene) and the results compared with modified and unmodified SFE, enhanced fluidity solvent (EFS) extraction and Soxhlet extraction. From the results obtained (Figure 16) the 16 PAHs studied could be divided in three distinctive groups: low-, mediumand high-molecular weight species. The low-molecular weight species were characterised by low recoveries $(0-70 \%)$. The poor recoveries of acenaphthylene and acenaphthene were suggested to be due to the decomposition of these compounds after adsorption on to the fly ash. This kind of behaviour has also been observed by other researchers $/ 31-33 /$. The PFE methods recovered the medium-molecular weight PAHs better than Soxhlet extraction (Figure 16) with efficiencies which ranged from 56 to $132 \%$. The exception was anthracene which was suggested to undergo decomposition as described above. The highest extraction efficiencies were obtained using PFE with toluene as the extraction solvent. For the high-molecular weight species PFE with toluene, as the extraction solvent. gave the best recoveries (83-108\%) but high standard deviations were observed $(>20 \%)$. Statistical analysis of the data demonstrated equivalence between all the PFE approaches. The most consistent recoveries (53-57\%) for PFE were obtained using methylene chloride with the static step (standard 


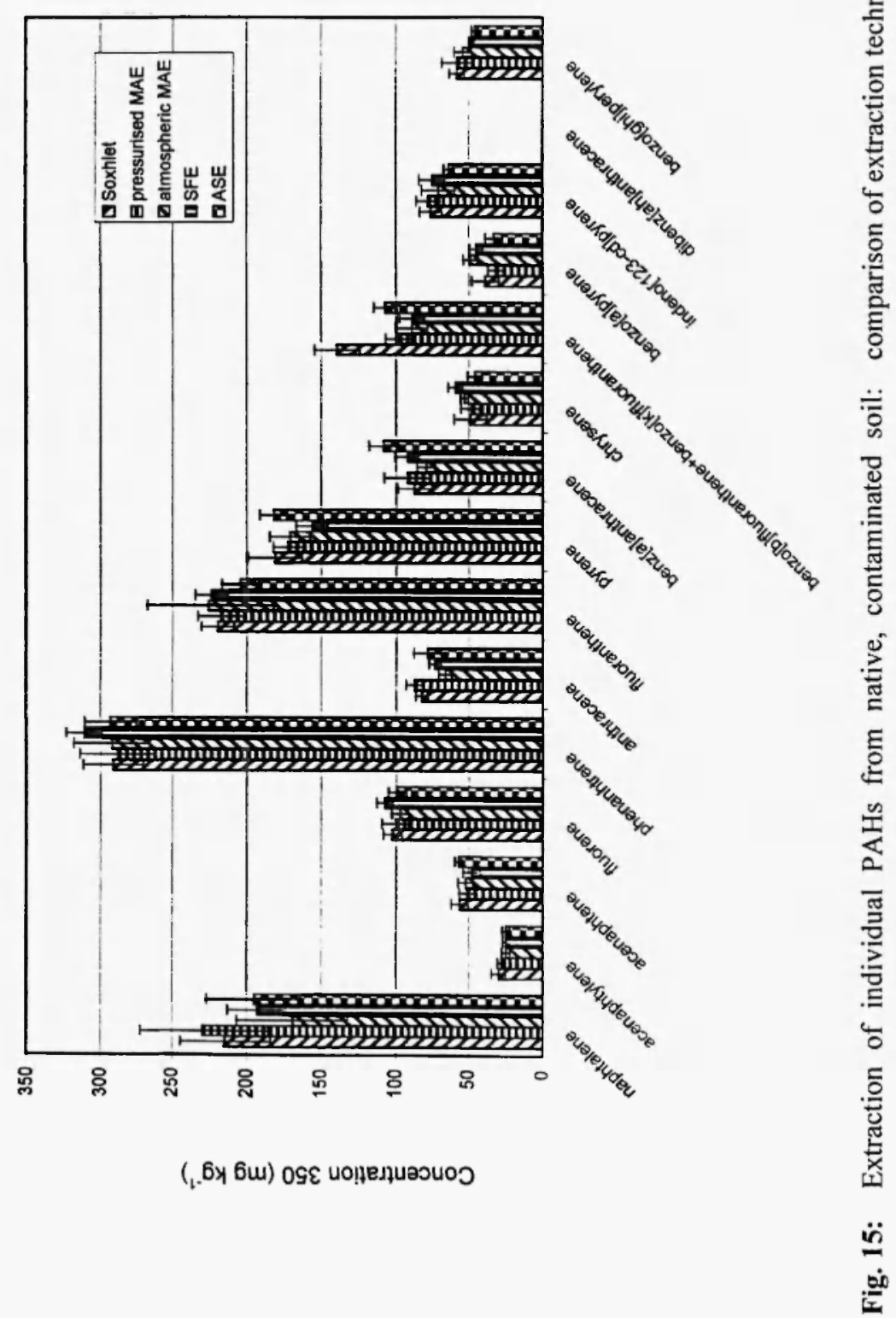




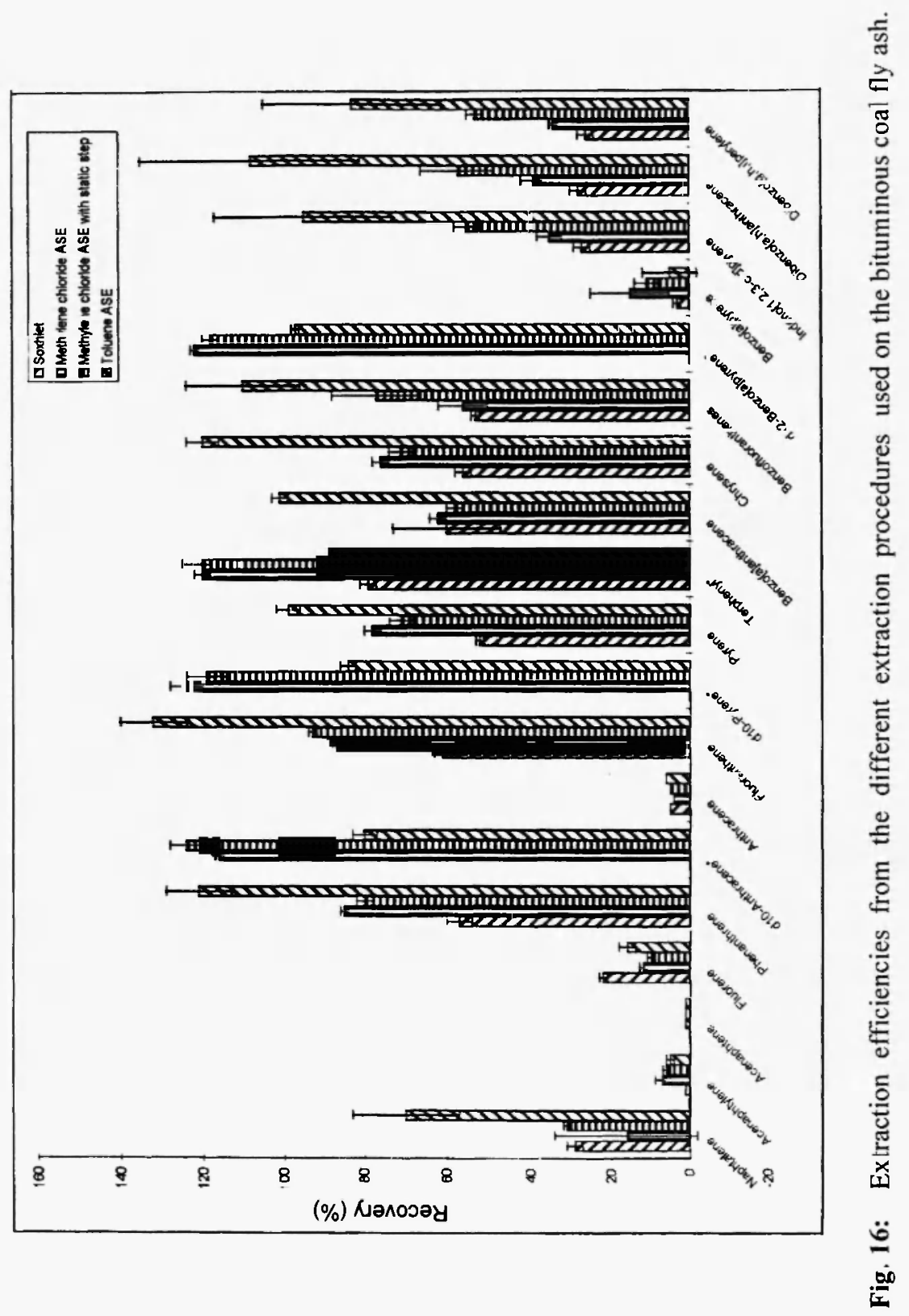


deviation $<9 \%$ ). The low recoveries of benzo[a]pyrene were associated with decomposition as described above. A two-way analysis of variance (ANOVA) showed that all three PFE extraction procedures were significantly better than the Soxhlet procedure for medium- and high-molecular weight PAHs. Using the Student's $t$-test at the $95 \%$ confidence level and comparing the overall recovery means, there was no statistical difference between the different PFE procedures. The recoveries obtained from the bituminous fly ash were poorer than the ones obtained from a previous study on the extraction of PAHs from lignite fly ash /34/. Both fly ash matrices were similar in moisture content, particle sizes, elemental composition, etc. but they differed in the carbon content $(0.2 \%$ and $15 \%$ for the lignite and bituminous fly ash matrices, respectively). The high carbon content of the bituminous fly ash made the matrix more adsorptive and thus more rigorous extraction procedures were required. This study illustrates the difficulty in developing and adapting analyte-specific extraction methods for different matrices.

Richter et al. /4/ studied the effect of pressure, temperature and solvent volume on the extraction of PAHs and TPHs from spiked silicas and then applied the procedure to two reference materials (SRM 1649 and HS-3). No trend was seen with respect to pressure effects on the recoveries of PAHs from spiked dry silicas. However, a trend was seen with wet silicas with 300 $\AA$ pore material. The results (Figure 17) demonstrate improved recoveries as pressure is increased from 1000 to 2500 psi. It is suggested that elevated pressure forces solvent into the pores, releasing the analyte, which have been effectively blocked by the water. An increase in temperature $\left(25\right.$ to $\left.100^{\circ} \mathrm{C}\right)$ also gave improved recoveries and precision of TPHs from ERA certified soil (Figure 18). The solvent volume needed to complete extraction was also studied on the ERA certified soils. The authors concluded that the amount of solvent needed to achieve quantitative extraction of TPHs can be expressed as 1.2-1.5 times the volume of the empty extraction cell used to contain the sample. Finally, PAHs were extracted from SRM 1649 (urban dust), HS-3 (Canadian marine sediment) and the ERA soil using the optimized conditions. Good recoveries and RSD values were obtained for the reference urban dust (88.5-125\% recovery with $2.0-6.7 \%$ RSD). Only four of the compounds were outside the $90 \%$ confidence interval for the certified values of HS-3: anthracene (lower recovery), benzo[ $b]$ fluoranthene, benzo[ $k]$ fluoranthene and dibenz $[a, h]$ anthracene (higher recoveries). To determine the 


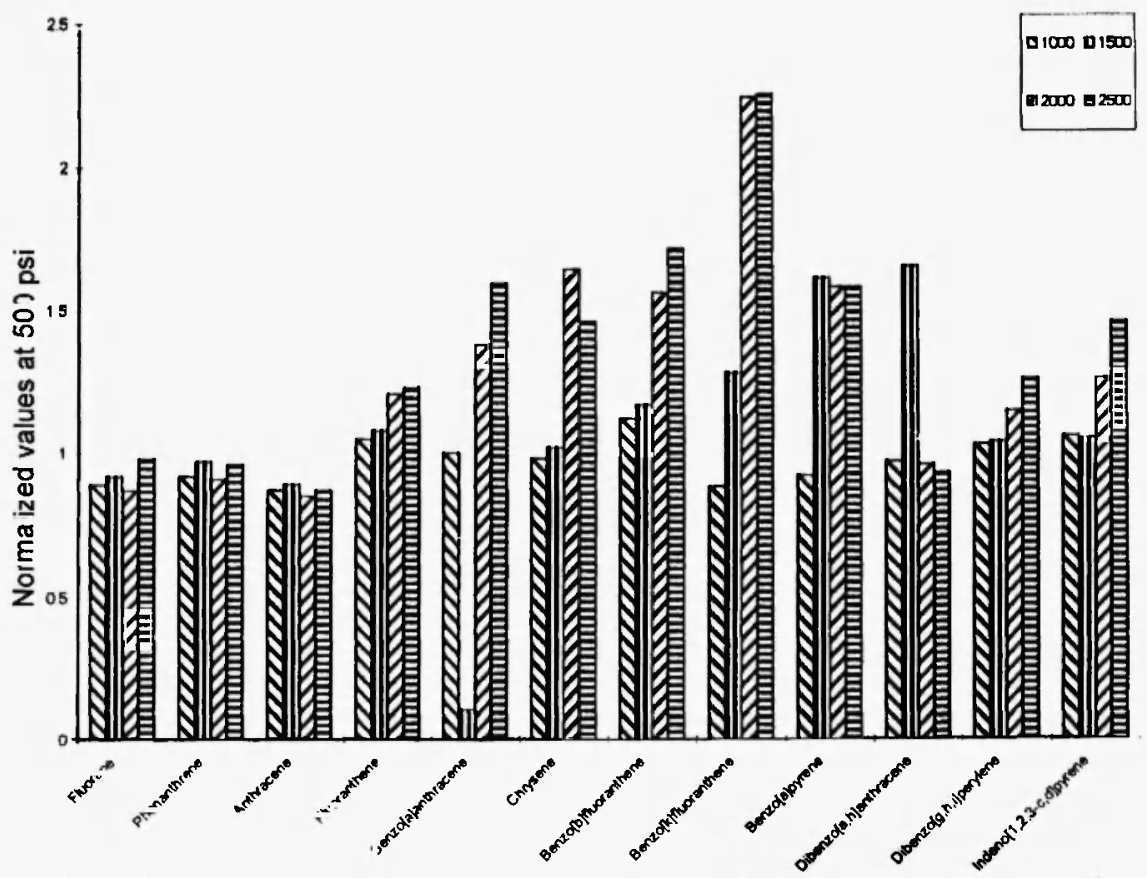

Fig. 17: Effect of pressure on PAH recovery from water-coverded silica (300 A).

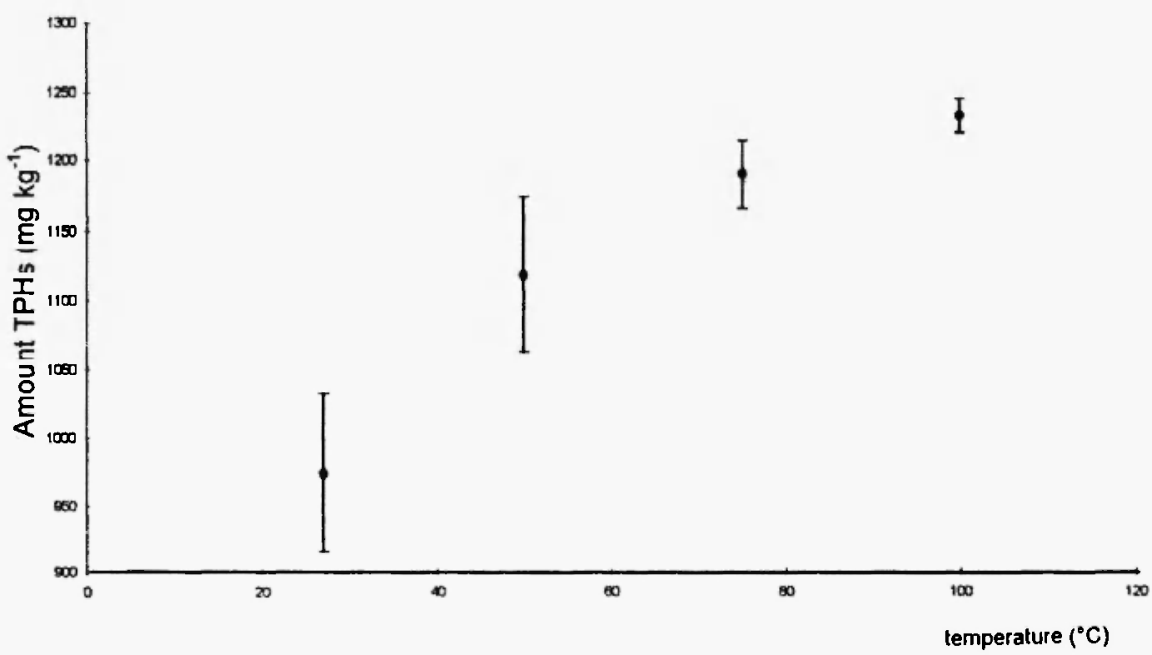

Fig. 18: Effect of temperature on the recovery of TPHs from soil using ASE (1200 $\mathrm{mg} \mathrm{kg}^{-1}$ certified value). 
reproducibility of PFE eighty-five samples (4-8 g) of ERA soil were extracted sequentially with an average recovery of $103 \%$ with $2.7 \%$ RSD.

Popp et al. $/ 15 /$ tested three different solvents or solvent mixtures (acetone-hexane, acetone-methylene chloride and toluene) for the extraction of PAHs from two real soil samples. The results are shown in Figure 19. It is observed that the highest recoveries in all cases were obtained using toluene as the solvent. Another natively contaminated sample was extracted using toluene and the results compared to Soxhlet extraction (16 hours with toluene). In almost every case the recoveries were greater using PFE, the exception was benz $[a]$ anthracene.

The effect of operating variables on the extraction of PAHs from SRM 1944 (New York/New Jersey waterway sediment) was studied by Schantz $e t$ al. $/ 13 /$ At a constant temperature of $100^{\circ} \mathrm{C}$ the pressure was varied between 1000 and 2200 psi. The concentration of the selected PAHs extracted increased slightly with pressure but reached a plateau at 2000 psi. At a constant value of pressure $(2000 \mathrm{psi})$ the temperature was varied from 50 to $150^{\circ} \mathrm{C}$. For the selected PAHs, the amount extracted leveled off at $100^{\circ} \mathrm{C}$. Using the optimized values of temperature $\left(100^{\circ} \mathrm{C}\right)$ and pressure $(2000 \mathrm{psi})$ different extraction solvents were tested on different certified reference materials. For SRM 1649a (urban dust) the three different solvents tested (methylene chloride, hexane-acetone and acetonitrile) gave concentration values that agreed with the Soxhlet extraction values. For SRM 1650 and SRM 2975 (diesel particulate material) methylene chloride, toluene and toluene-methanol were tested and the results from the three different solvents were comparable. The concentrations obtained for some of the highmolecular-weight PAHs (benzo[ghi]perylene, indeno[1,2,3-cd]pyrene, dibenz $[a, j]$ anthracene, picene and benzo $[b]$ chrysene) in SRM 2975 were $17-40 \%$ higher than those obtained by Soxhlet. These findings suggested that PFE extracted more of the high-molecular weight PAHs from the diesel particulate materials. For SRM 1650, the values obtained by PFE were compared with the reference values (determined using Soxhlet extraction) and they were all in good agreement except for benzo[ghi]perylene for which the concentration was $173 \%$ higher than the previous Soxhlet concentration. The authors extracted benzo[ghi]perylene by Soxhlet again and the results obtained agreed with those obtained by PFE. Thus, it was suggested that the original certification result was in error. Two sediment materials (SRM $1941 \mathrm{a}$ and SRM 1944) were extracted by PFE with different solvents 


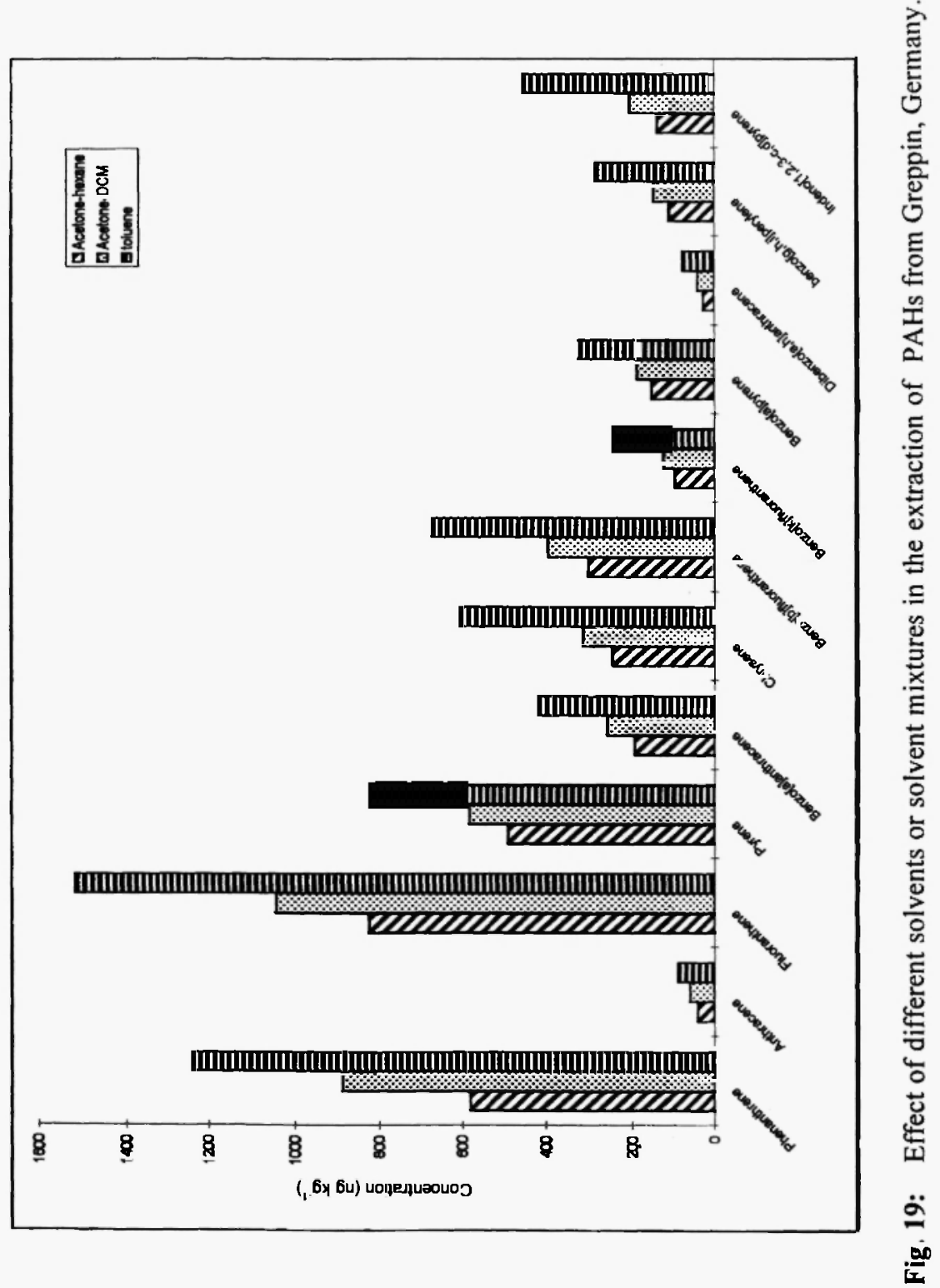


(methylene chloride, acetonitrile and hexane-acetone) and the results were in good agreement with both the certified and Soxhlet values.

Richter et al. 135/ extracted PAHs from SRM 1649 (urban dust) using PFE. The PFE conditions were as follows: pressure, $2000 \mathrm{psi}$; temperature, $100^{\circ} \mathrm{C}$; extraction time, 10 mins $(5$ mins heatup followed by 5 mins static extraction); nitrogen flush, 100 psi for 30s; and, solvent, methylene chloride:acetone $(1: 1, v / v)$. Average recoveries $(n=2)$ ranged from $83.5 \%$ to $126.9 \%$. Chen et al. $/ 36 /$ interfaced PFE with HPLC for the extraction of PAHs from soil samples. On-line coupling of PFE with HPLC did not lead to significant loss of resolution or peak shape. The chromatograms also showed similar retention times for loop injection and on-line coupling. The approach was applied to the analysis of a certified standard soil (ERA, QCS 345). The results obtained by PFE-HPLC with fluorescence detection were within the limits of the certified values.

Jensen et al. $/ 37 /$ extracted PAHs from several reference materials using PFE. SRS 103-100 was extracted both with PFE and Soxhlet with recoveries ranging from 83.4 to $142.3 \%$ were obtained with PFE compared to Soxhlet. HS-3 marine sediment was also extracted by PFE; three compounds were found to be outside the $90 \%$ confidence interval for the certified values: anthracene, benzo[b]fluoranthene, benzo[ $k]$ fluoranthene and dibenz $[a, h]$ anthracene. The recovery for anthracene was lower than the certified value whereas the recovery for benzo[b]fluoranthene, benzo[ $k]$ fluoranthene and dibenz $[a, h]$ anthracene was higher. It was suggested that the higher recoveries obtained for the latter compounds were probably due to co-elution with interferent compounds.

Different drying, extraction and detection techniques for the extraction of PAHs from native contaminated soil samples were compared by Berset $e t$ al. 138/. The extraction techniques studied were: Soxhlet extraction, alkaline saponification, SFE, PFE, ultrasonic extraction and mechanical shaking. Pressurised fluid extraction was performed with a mixture of hexane:acetone:toluene $(10: 5: 1)$ at $13.8 \mathrm{MPa}$ and a temperature of $100^{\circ} \mathrm{C}$. Methanolic saponification, SFE and PFE were more efficient than sonication whereas Soxhlet and the mechanical shaking extraction showed median values which corresponded exactly to the overall mean of all extraction procedures. Soxhlet extraction showed the smallest variations in the results. However, Soxhlet extraction relied upon long extraction times (18 hours) and large solvent volumes $(160 \mathrm{ml})$. Pressurised fluid extraction was the quickest extraction method $(0.25 \mathrm{~h})$, while PFE and SFE consumed less solvent than 
the other extraction methods ( 30 and $9.3 \mathrm{ml}$, respectively). However, these latter techniques require more time for method development and have higher capital costs.

\section{Volatile organic compounds}

Volatile organic compounds (VOCs) is a general term that includes a wide range of naturally-occurring and synthetic compounds which have the potential to enter the atmosphere under normal conditions of use. VOCs are found in everything from adhesives, coatings and inks, aerosol sprays, metal cleaning and dry cleaning, and many industries rely on the use of solvents at intermediate points in their production processes $/ 28$.

Benzene, toluene, ethylbenzene, xylene and cumene were extracted from a vapour-fortified clay soil ( $\mathrm{pH} 5.3$, LOI $16 \%$ ) by Meney et al. $/ 8 /$ using methanol at elevated temperature $\left(100\right.$ or $\left.150^{\circ} \mathrm{C}\right)$ and pressure $(100$ or 150 bar) for 5 or $30 \mathrm{~min}$ in a 'home-made' system. A small increase in the amounts of analytes extracted was apparent for the lower temperature and pressure conditions, but with an accompanying loss of precision. The longer extraction time did not improve recoveries. The operating conditions selected were therefore: pressure, $150 \mathrm{bar}$; temperature, $150^{\circ} \mathrm{C}$; and, extraction time, 5 min. Since analyte losses due to volatilization were anticipated, collection was performed with the glass vial cooled in an ice-salt mixture (temperature $\sim-3^{\circ} \mathrm{C}$ ). Figure 20 shows the influence on collection efficiency of cooling in an ice-salt bath. The developed "elevated temperature and pressure solvent extraction" (ETPSE) method was compared with a commercial PFE system working on the manufacturer's recommended conditions $\left(2000 \mathrm{psi} ; 100^{\circ} \mathrm{C}\right.$; and 5 mins). Similar levels of ethylbenzene, p-xylene and cumene were extracted with the two systems (Figure 21) but the recoveries and, in particular, the precision for benzene and toluene were significantly better with ETPSE. This was probably because the PFE did not have a cooling system for the vials. Richter $e t$ al. $/ 4$ / performed the extraction of BTEX from a spiked clean sand with methylene chloride at $60^{\circ} \mathrm{C}$ at 2500 psi with 5 min equilibration and $5 \mathrm{~min}$ static heat. Good recoveries $(97.1-100 \%)$ and good RSD values $(0.9-3.7 \%)$ were obtained.

\section{Polychlorinated biphenyls}

Chlorinated biphenyls (CBs) were produced to use as dielectric fluids in transformers and capacitors, and as plasticisers in paint and rubber sealants 


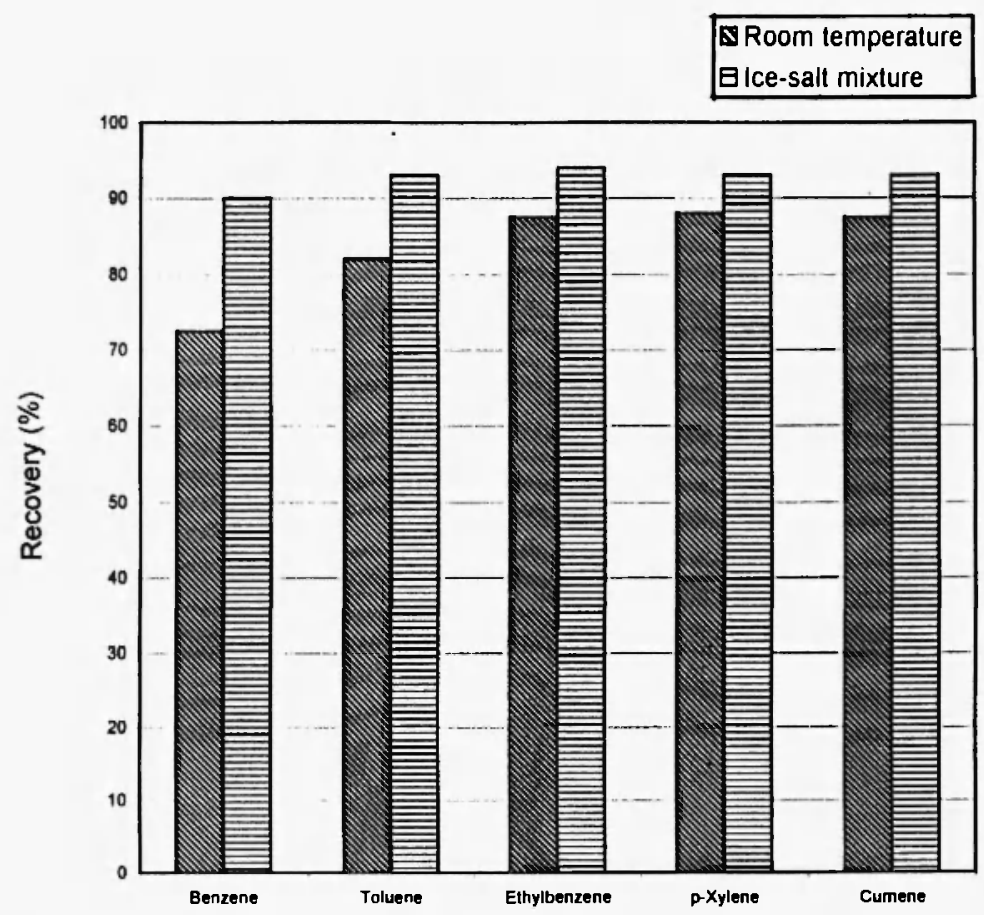

Fig. 20: Collection efficiencies with and without cooling of the collection vial

from 1930 until 1983. Since CBs are chemically and physically very stable, their residence time in the environment is very long and they tend to accumulate in sediments and biota $/ 39 /$.

Zuloaga et al. /40/ optimized the extraction of PCBs from a natively contaminated soil, and then applied the developed method to the extraction of PCBs from certified industrial soil (CRM 481). They then compared the extraction yields with those obtained by microwave-assisted extraction (MAE) and Soxhlet extraction. A central composite design was built to optimize pressure $(1000-2400 \mathrm{psi})$, temperature $\left(70-180^{\circ} \mathrm{C}\right)$ and extraction time (2-16 mins) while a mixture of acetone:hexane (75:25, v/v) was used as the extraction solvent. From the results obtained, the authors concluded that the three operating variables had an influence on the extraction yield and the optimum conditions were calculated by a modified Simplex method /41/ implemented in the MultiSimplex /42/. Under the optimum conditions samples of CRM 481 were extracted and the results were in good agreement 


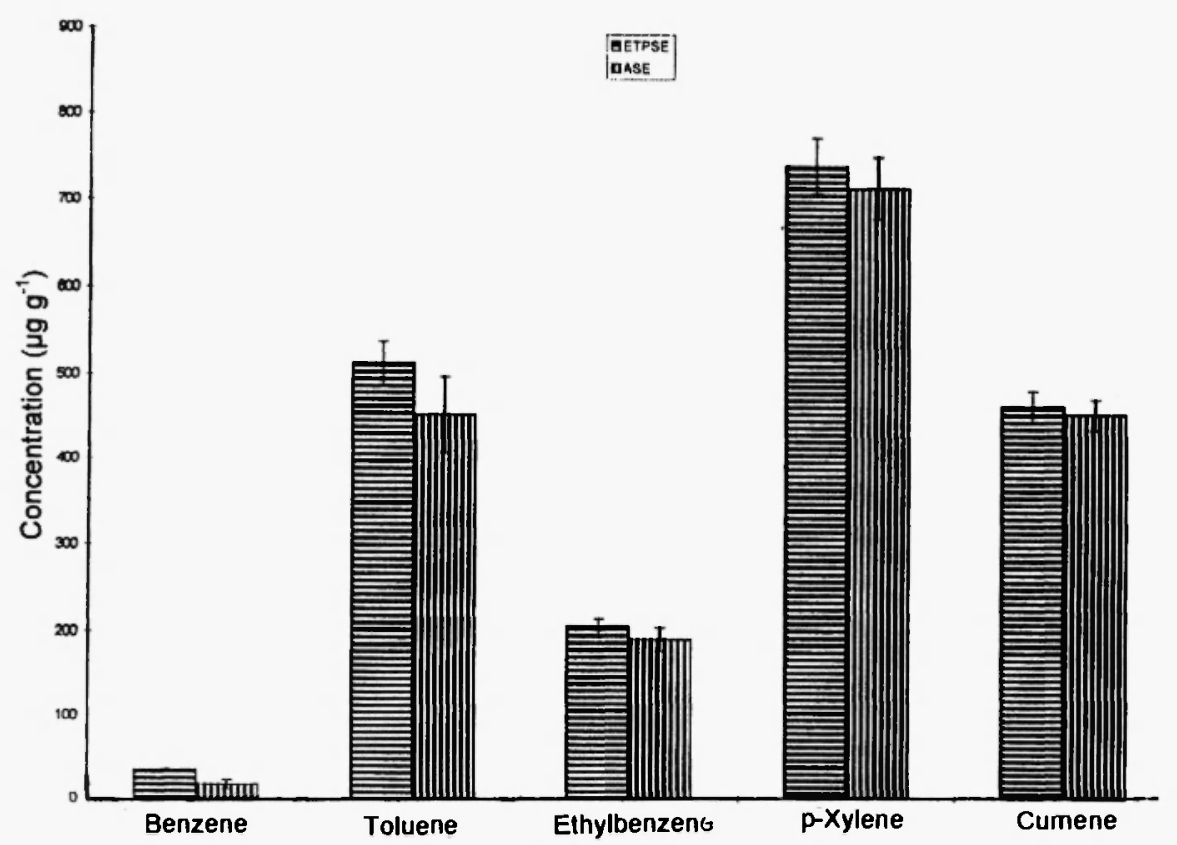

Fig. 21: Amounts of analytes extracted from vapour fortified dry clay soil by ETPSE and ASE $\left(\mu g g^{-1} n=4\right)$

with those obtained by MAE and Soxhlet extraction and the certified values. Figure 22 shows the values obtained for four CBs.

Richter et al. $135 /$ extracted Aroclor 1254 from a standard reference material (CRM 911-050) using EPA method 3545 conditions /1/. Average recoveries of $99.1 \%$ and RSD of $3.71 \%$ were obtained. Similarly, Richter et al. /4/ extracted PCBs from a sewage sludge sample. Recoveries based on the results by Soxhlet ranged from $86.3 \%$ to $90 \%$. The influence of solvent on the extraction of PCBs was investigated by Schantz et al. /13/. They extracted PCBs from SRM 1649a (urban dust), SRM 194la (marine sediment) and SRM 1944 (waterway sediment) using PFE and three different solvents (hexane-acetone, acetonitrile and methylene chloride). Figure 23 shows the results obtained for SRM 1649 a, which are in good agreement with Soxhlet values.

The extraction of PCBs from several reference materials has been reported by Bjorkland et al. /16/. PCBs were extracted from marine sediment SRM 1944. The mean recovery for all investigated congeners was $99 \%$ 


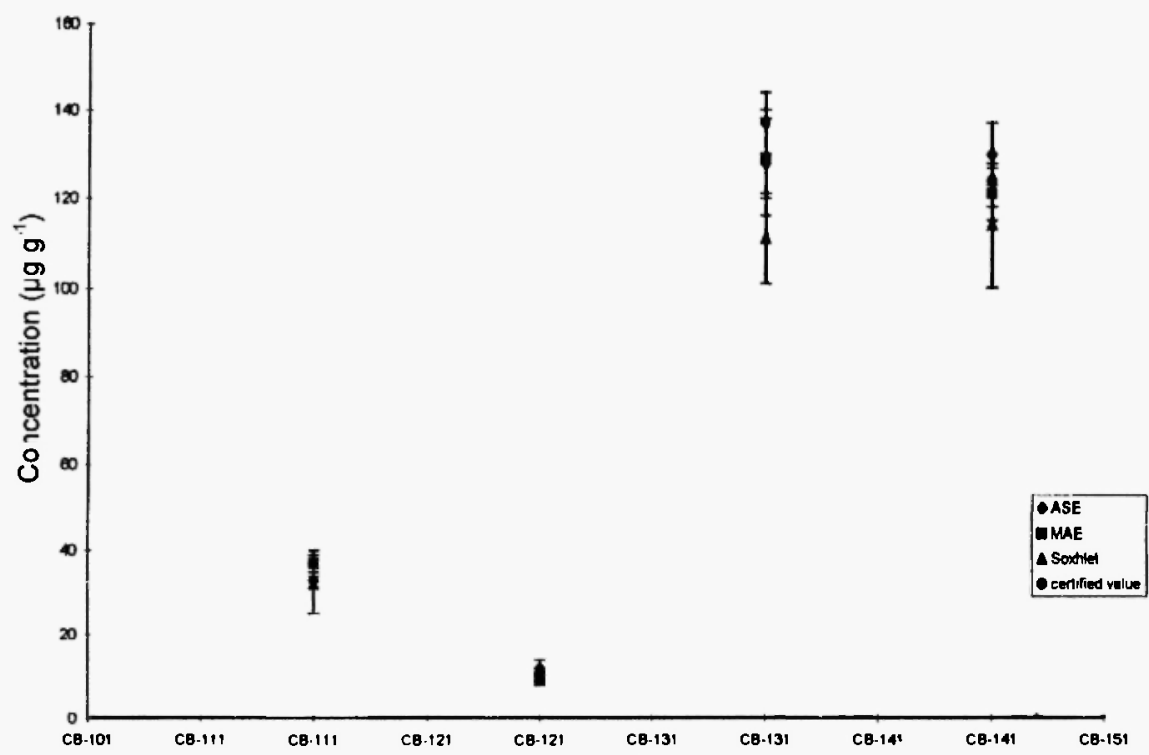

Fig. 22: Comparison of ASE, MAE and Soxhlet extraction of PCBs from CRM 481.

compared to certified values after a $5 \mathrm{~min}$ static heat at $100^{\circ} \mathrm{C}$. The average concentration of PCBs found in the second static step was $0.8 \%$ and therefore considered to be negligible. The standard deviations were below or close to $5 \%$. PCBs were also extracted from sewage sludge BCR 392. The average recovery for the six congeners investigated was $101 \%$. In the second static step only $1.4 \%$ of the concentrations detected in the first step were detected. The standard deviations never exceeded $5 \%$. The last reference material studied was a harbour sediment, CRM 536. The average recovery of the congeners studied was $107 \%$, but in this case $7 \%$ of the concentrations in the first step were extracted in the second step. The RSD values were also normally higher than $7 \%$. When the concentrations in the two extration steps were added an average recovery of $114 \%$ and RSD values around $5 \%$ were obtained. The authors thought that the lower recoveries and larger RSD values obtained for this reference material were due to large differences in particle size ( $75-1000 \mu \mathrm{m}$ for $80 \%$ of the material, $>1000 \mu \mathrm{m}$ for $10 \%$ of the material and $<75 \mu \mathrm{m}$ for $10 \%$ of the material), leading to a more inhomogeneous diffusion path distribution and consequently different degree 


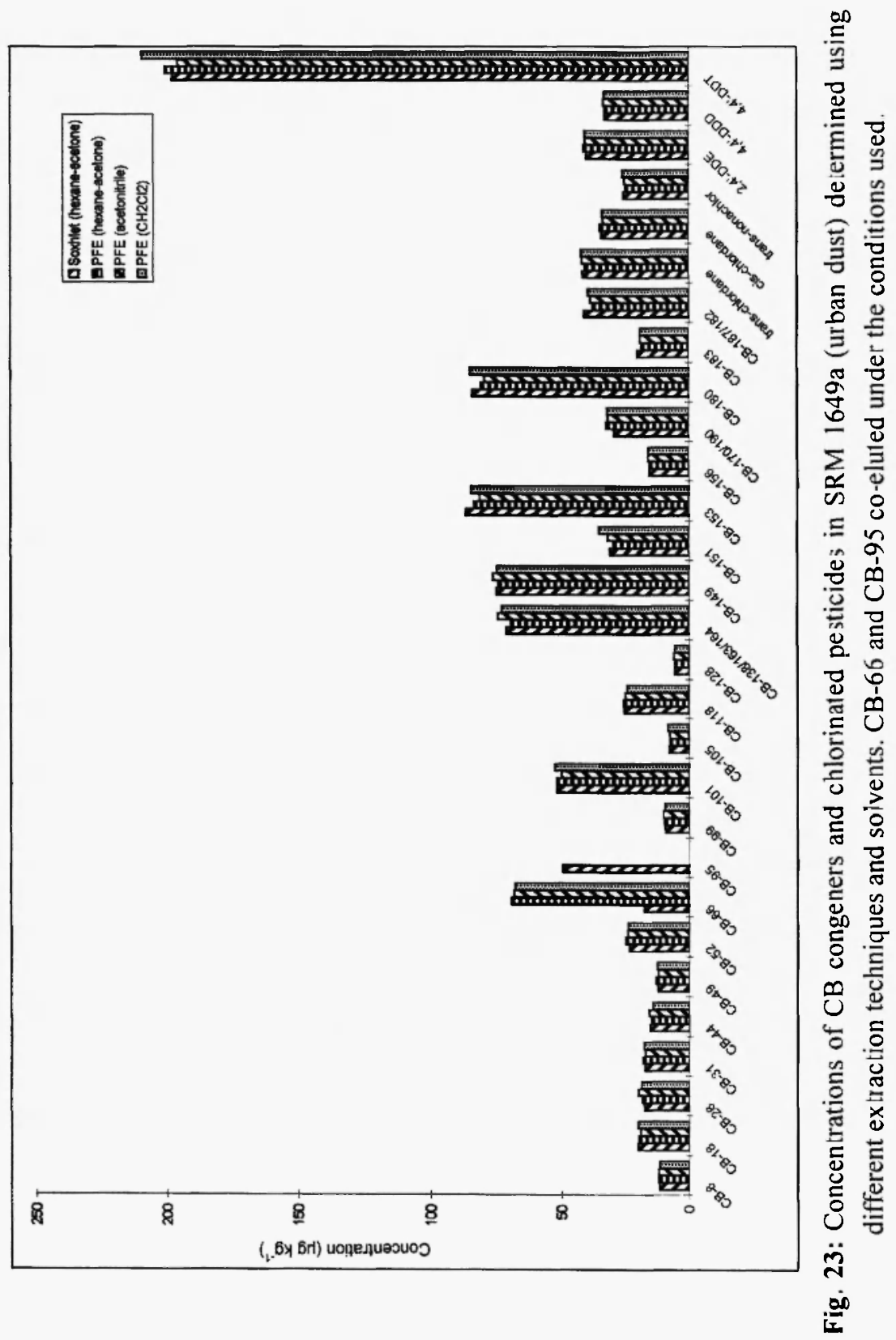


of entrapment of the analytes. The results suggested that 5 mins might not always be enough to assure a completely exhaustive extraction for very inhomogeneous samples and it might be advantageous to perform a $2 \times 5 \mathrm{~min}$ extraction. When extracting CRM 536 with a smaller particle size $(<15 \mu \mathrm{m})$ the average recovery was $122 \%$ and $\mathrm{RSD}$ values were usually close to $2 \%$. The higher recoveries obtained were probably an indication that the PCBs in the small particle material were more accessible. PFE was also compared to SFE; higher recoveries were obtained for PFE. This might be due to the cleaner extracts obtained with SFE and that interferences might be the cause of the higher recoveries obtained with PFE.

Wenzel et al. /43/ extracted PCBs from pine needles and mosses. When applying the conditions suggested by Dionex $/ 44 /$, i.e. $1: 1 \mathrm{v} / \mathrm{v}$ $\mathrm{n}$-hexane-acetone at a temperature of $100^{\circ} \mathrm{C}$ and an extraction time of $1 \times 5$ min, lower recoveries than those obtained by ultrasonic extraction were obtained. When changing the solvent to pure $n$-hexane, in a temperature range from $21-170^{\circ} \mathrm{C}$, the best recoveries were obtained at $40^{\circ} \mathrm{C}$. Under these conditions PCBs that could not be detected by ultrasonic extraction were measured. Similar results were obtained with toluene but since it took longer to blow it down, n-hexane was chosen as the extraction solvent. Placing a mixture of Florisil/ $\mathrm{Al}_{2} \mathrm{O}_{3}$ into the extraction vessel also enabled preliminary clean-up of the needle extracts to be done in-situ.

\section{Dioxins and Dibenzofurans}

Polychlorinated dibenzo-p-dioxins (PCDDs) and dibenzofurans are well known environmental pollutants of high toxic potential /45/. They are sub-products of the synthesis of some pesticides (pentachorophenol) and PCBs and they can also appear in incineration processes.

Pressurised fluid extraction has been used for the extraction of PCDD/F from fly ash originating from a municipal incineration plant $/ 15 /$. Toluene was chosen as the extraction solvent at $200^{\circ} \mathrm{C}$. Extraction times of $2 \times 5$ min and $2 \times 10$ min were chosen; extraction yields increased with extraction times but were still lower than the recoveries obtained by Soxhlet extraction, especially when the degree of chlorination increased. To overcome this problem an $\mathrm{HCl}$ pre-treatment step prior to Soxhlet and PFE extraction was tested. This resulted in higher extraction yields for both procedures, with the highest extraction yields being obtained by PFE (Figure 24). 


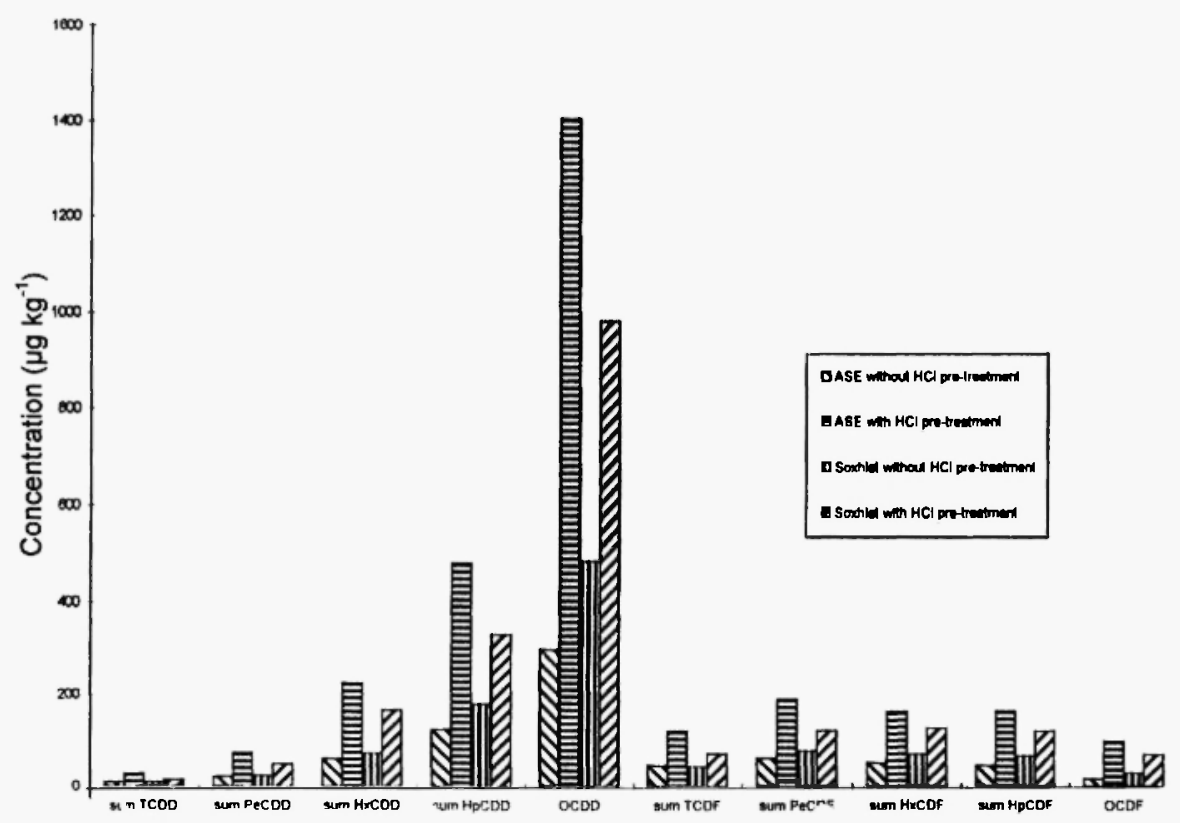

Fig. 24: $\quad \mathrm{PCDD} / \mathrm{F}$ concentrations of a fly ash sample for ASE and Soxhlet extraction with and without acid pre-treatment step.

Richter et al. /45/ extracted PCDD/Fs from chimney brick, urban dust, fly ash, soil and three sediment samples. Instead of pre-treatment with $\mathrm{HCl}$ for the extraction of the fly ash, glacial acetic acid at $5 \%(v / v)$ was added to the toluene for the extraction. The data obtained indicated that PFE gave essentially equivalent data to Soxhlet extraction but with shorter extraction times and a requirement to use less solvent.

Bautz et al. 146/ used dynamic high pressure solvent extraction (DHPSE) (DHPSE is the registered name of the utility model Register No. DE 39702 $865 \mathrm{U}$ ) to extract PCDD/Fs from fly ash and environmental matrices (filter dust and soil samples). DHPSE is a process that continuously uses fresh solvent under elevated temperatures and pressures to achieve extraction. Generally, the concentration of PCDD/Fs determined by DHPSE exceeded that of Soxhlet extraction. In order to exclude the possibility of PCDD/Fs formation from other organic compounds present in the sample at high temperatures and pressures, chlorophenols, benzenes and PCBs were spiked on to a PCDD/F-free sample and extracted by DHPSE. No formation of dibenzodioxins or furans was observed. It was concluded that the DHPSE 
approach gave better recoveries than the Soxhlet extraction procedure. In addition, the acid pre-treatment of fly ash, as discussed above, did not significantly improve the results obtained with DHPSE for the untreated sample. When the authors tried the toluene-glacial acetic mixture as suggested by Richter et al. $14 /$, inconsistent results were obtained. Thus, in the authors' opinion, the screening of unknown samples by DHPSE may be employed without a time-consuming acid pre-treatment step. Static and dynamic extractions were also compared in this work. Better results were obtained by dynamic extraction; static extraction requires several cycles to achieve satisfactory extraction results.

\section{Pesticides and Herbicides}

Richter et al. /4/ studied the possible degradation of DDT (into DDD and DDE) and endrin (into endrin aldehyde and endrin ketone) under PFE extraction conditions. DDT and endrin were separately spiked (spike level 5 $\mu \mathrm{g} \mathrm{kg}^{-1}$ ) on to sand and extracted at an elevated temperature of $150^{\circ} \mathrm{C}$ (normal extraction temperature is $100^{\circ} \mathrm{C}$ ). No evidence for the presence of breakdown products of DDT (i.e. DDE and DDD) or endrin (endrin aldehyde and endrin ketone) were observed.

Ezzel et al. /47/ extracted organophosphorus pesticides and herbicides from three different spiked matrices (clay, loam and sand) at two different concentration levels (the low level was approximately $250 \mu \mathrm{g} \mathrm{kg}^{-1}$, whilst the high level was approximately $2500 \mu \mathrm{g} \mathrm{kg}^{-1}$ ). For the extraction of herbicides, samples were acidified by adding phosphoric acid directly to the extraction solvent. No matrix dependence on recovery was observed.

Schantz et al. /13/ extracted chlorinated pesticides from SRM 1649a (urban dust), SRM 1944 (waterway sediment), SRM 2974 (organics in freeze-dried mussel tissue), and CARP I and II (ground whole carp) using PFE and three different solvents (hexane-acetone, acetonitrile and methylene chloride). Good agreement was obtained in all cases with either the certificate values or Soxhlet using methylene chloride (SRM 1944, CARP I and CARP II) or hexane-acetone (SRM 1649a). In addition, chlorinated pesticides were also extracted from SRM 1941 (marine sediment) using methylene chloride; results were in agreement with certificate values and Soxhlet (Figure 23).

The extraction of chlorinated pesticides from natively polluted soil samples has been reported /15/. In this work, the number of extractions per sample was varied. It was found that the predominant part of the 


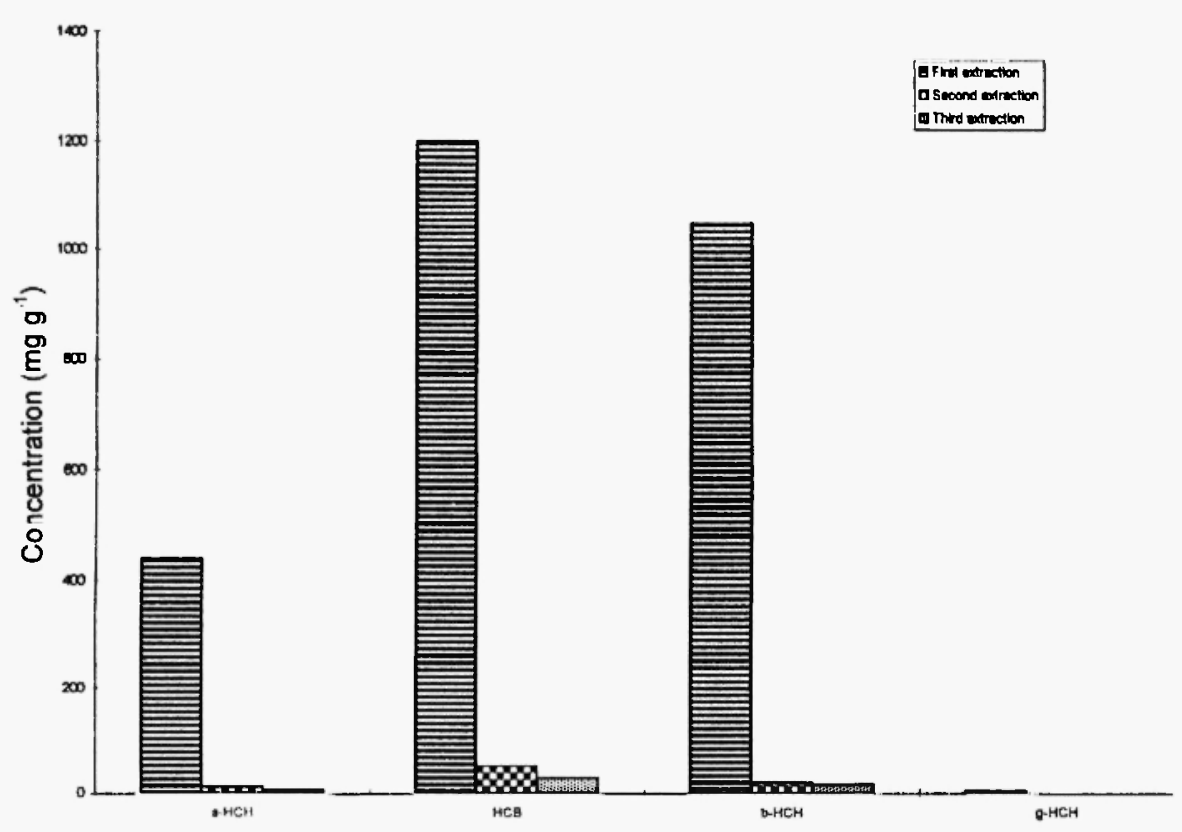

Fig. 25: Results of $3 \times 5$ min ASE extractions of contaminated soils with acetone:hexane (1:1).

contaminants was extracted during the first extraction step, that the yield of the second extraction was much lower (but not negligible) and that the yield of the third procedure was very low (Figure 25). Different solvents (acetone-hexane, methylene chloride-acetone and toluene) were also evaluated. In the case of difficult matrices and high concentrations of pollutants the use of toluene as the extraction solvent was preferred.

Chlordane has been extracted from a range of spiked soils using PFE, SFE and Soxhlet extraction /48/. Perhaps unsurprisingly, similar results were obtained by each approach. In addition, PFE was applied to the extraction of chlordane from a Superfund site soil (Region 9) and a certified reference material (SRM 1941). The results obtained were as follows: 3.05 and 24.3 ppb in the soil and SRM 1941, respectively. Previous work had identified that the anticipated levels of chlordanes ( $\alpha$-chlordane, $\gamma$-chlordane, heptachlor and trans-nonachlor) were at the 1 to 2 ppb levels.

Pyle and Marus /49/ extracted and analysed chlorinated pesticides in the low ppb range from SRM 1941 (organics in marine sediment) and a natively polluted soil sample using $\mathrm{PFE}$ and GC/MS/MS. Extracted organic 

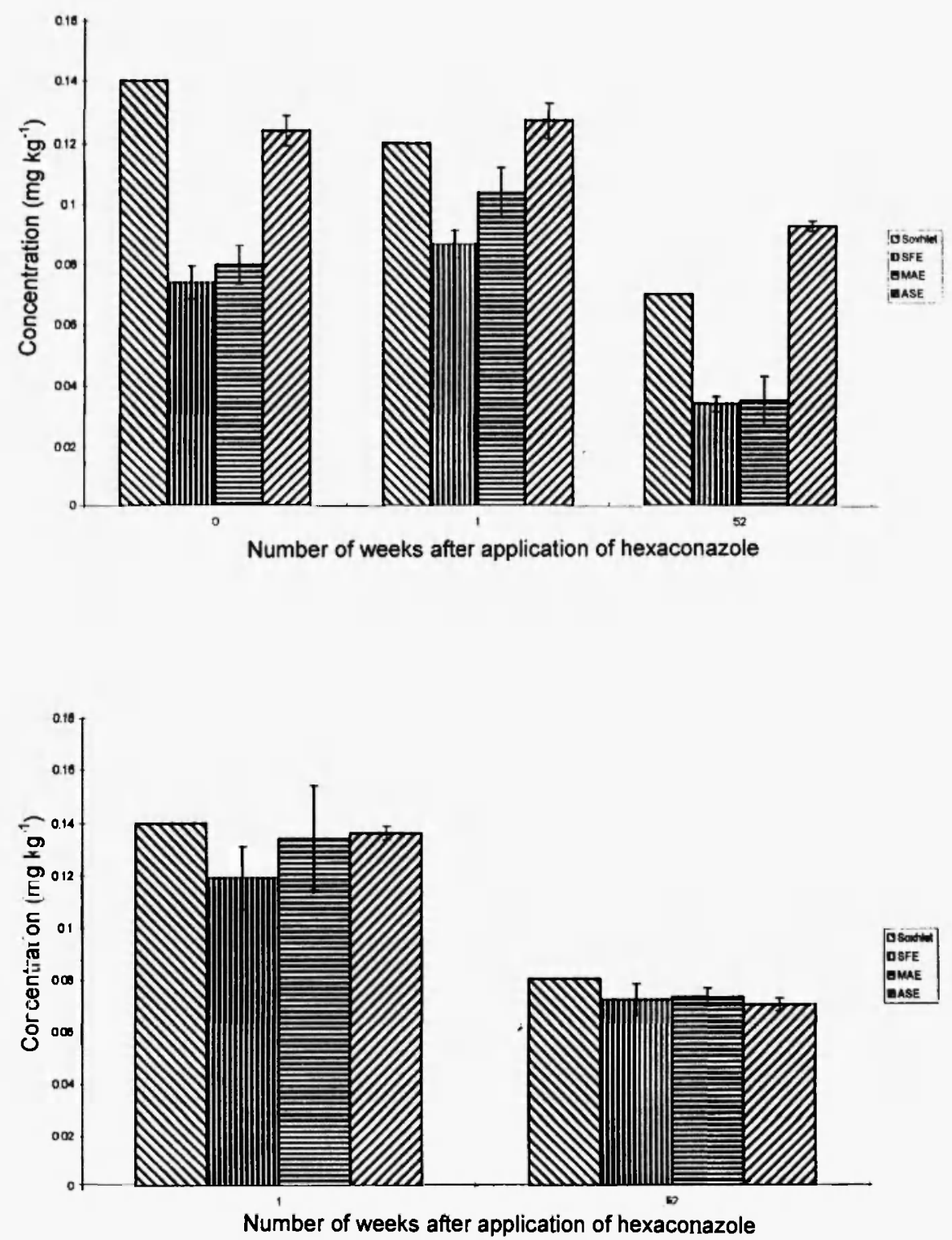

Fig. 26: Extraction of hexaconazole from aged soil sample: (a) soil A (sandy loam soil; $5.7 \%$ organic matter; $81 \%$ sand; $8 \%$ silt; $11 \%$ clay and $\mathrm{pH} 7.4$ ) and (b) soil B (sandy clay soil; $1.5 \%$ organic matter; $53 \%$ sand; $25 \%$ silt; $22 \%$ clay and $\mathrm{pH} 8.3$ ). 
compounds needed an additional clean-up owing to the extraction of non-target compounds as well as the target compounds. Although the 'warm' recovered extracts were clear, solid matter would precipitate upon standing at room temperature. In such cases, the extract was centrifuged at low speed and the supernatant decanted.

Diflufenican herbicide has been extracted from soil ( $\mathrm{pH} 7.8$, clay $40 \%$, silt $21 \%$, sand $35 \%$, organic matter $2.4 \%$, organic carbon $1.4 \%, 2 \mathrm{~mm} \mathrm{mesh}$ ) using PFE 150\%. Higher yields were obtained with PFE than with the traditional extraction procedure (shaking with acetonitrile). A comparison between the two approaches also identified the additional benefits of PFE i.e. automation, lower consumption of organic solvent, minimal risk to operator from solvent vapour and faster extraction time.

Frost et al. $127 /$ extracted hexaconazole from weathered soils using Soxhlet extraction, MAE, SFE and PFE. Hexaconazole was extracted from two different soils: soil $\mathrm{A}$ which was a sandy loam soil (5.7\% organic matter; $81 \%$ sand; $8 \%$ silt; $11 \%$ clay and $\mathrm{pH} 7.4$ ) while soil B was a sandy clay soil ( $1.5 \%$ organic matter; $53 \%$ sand; $25 \%$ silt; $22 \%$ clay and $\mathrm{pH} 8.3$ ). The extractions were done from soils that had been in contact with hexaconazole for different lengths of time. Figure 26 shows the yields obtained by the four different extraction techniques. For the soil with a lower organic matter content (soil B, 1.5\% organic matter) good recoveries were obtained for the three techniques when compared with Soxhlet. Better precision was also obtained by PFE. However, for soil A (high organic matter content, 5.7\%) recoveries showed greater variation. Only PFE gave results in good agreement with Soxhlet as well as good precision. In addition, apart from obtaining the highest recoveries and best precision, PFE also produced the cleanest chromatographic sample, with no interfering or co-eluting peaks.

Obana et al. /14/ extracted organophosphorus pesticides from foods using PFE. They studied three different solvent mixtures (cyclohexane-acetone $(1+1)$, dichloromethane-acetone $(1+1)$ and ethyl acetate-acetone $(1+1)$ ) for the extraction of organophosphorus pesticides in dried flour. The recoveries were good and independent of solvent type. The exception being dichlorvos were the recovery was $-40 \%$. The low recoveries of dichlorvos were attributed to analyte losses during the spiking procedure. Ethyl acetate-acetone $(1+1)$ mixture gave the worst precision (19-34\% RSD). When dealing with wet samples, the samples were mixed with a drying agent (diatomaceous earth, particle size $160-800 \mu \mathrm{m}$ ) and then ground in a mortar with a pestle until the mixture became homogeneous. The influence of 
extraction time, temperature and pressure were studied for the extraction of methamidophos and acephate from orange juice. Extraction time and temperature seemed to have no effect on extraction yields whereas higher pressures gave better recoveries (Figure 27). Ethyl acetate, toluene-acetone $(1+1)$, cyclohexane-acetone $(1+1)$, dichloromethane-acetone $(1+1)$, ethyl acetate-acetone $(1+1)$ and acetonitrile were studied for the extraction of the same pesticides from orange juice. Ethyl acetate gave the best recoveries (56 and $47 \%$ ). Pressurised fluid extraction was compared with hexane extraction for some of the pesticides in different foods and although slightly lower recoveries were obtained by PFE the precision was better. Okihashi $e$ t al. /51/ determined $\mathrm{N}$-methylcarbamate pesticides in foods using PFE. Yields of most of the pesticides were $70-100 \%$ with acceptable precision ( $<10 \%$ RSD). $N$-methylcarbamate pesticides were stable under the high temperature and pressure used by PFE.

Nemoto et al. /52/ extracted herbicides from soybeans using PFE. Due to the polar nature of the herbicide studied and their high solubility in water, water was initially used as the extraction solvent. However, when $100 \%$ water was used low and variable extraction volumes were obtained. The high

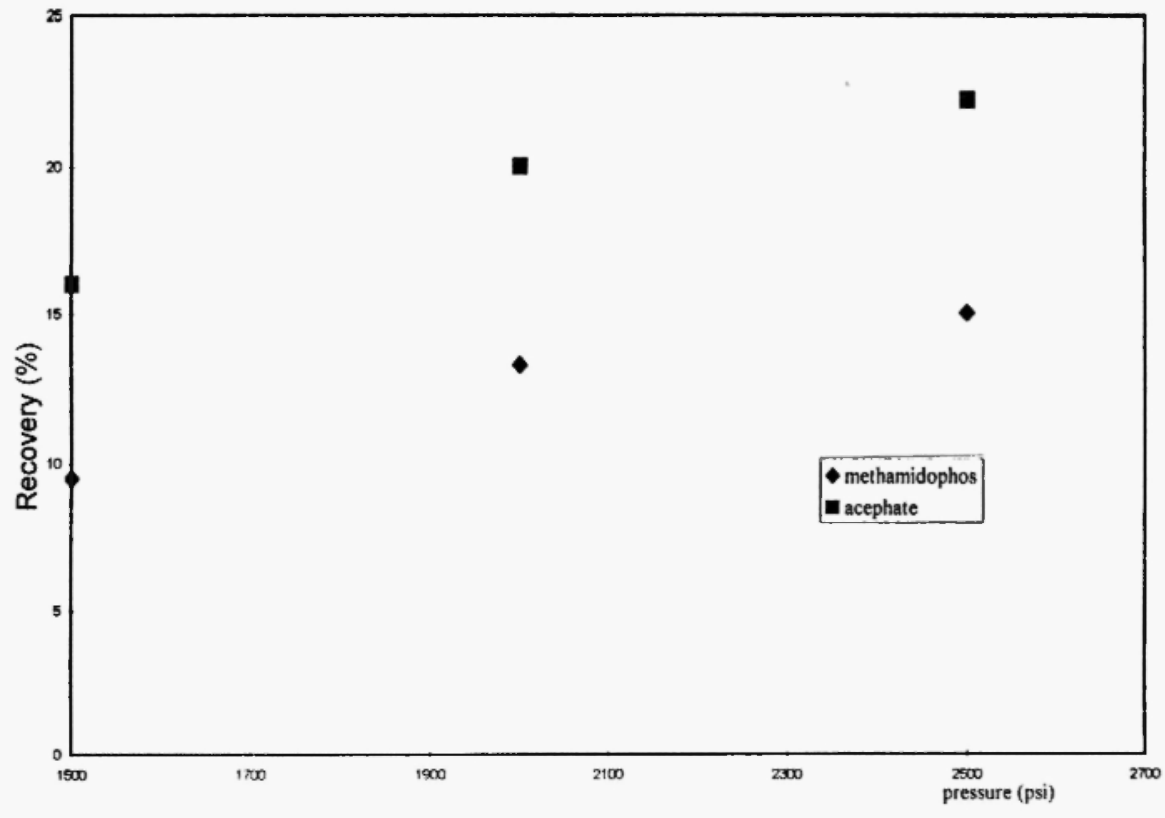

Fig. 27: Effect of the extraction pressure on recoveries of methamidophos and acephate from orange juice. 
viscosity of water coupled with the high levels of carbohydrates and proteins in soybeans made PFE difficult unless an organic solvent was added. The influence of $\mathrm{pH}$ on extraction efficiency was studied by adding $\mathrm{HCl}$ into the aqueous fraction of a $70 \%$ acetonitrile extraction solution. The use of $0.05 \mathrm{M}$ and $0.01 \mathrm{M} \mathrm{HCl}$ gave good recoveries for all the pesticides studied.

Wenzel et al. $/ 43$ / extracted chlorobenzenes, DDX and $\mathrm{HCH}$ isomers from pine needles and mosses. The best extraction conditions were at $120^{\circ} \mathrm{C}$ with n-hexane as extraction solvent. Only $\mathrm{DDE}$ and $\delta$ - $\mathrm{HCH}$ were better recovered at $170^{\circ} \mathrm{C}$. $\delta-\mathrm{HCH}$ was better recovered at higher temperatures because it possibly bonds strongly to plant tissues. However, under such high temperatures large quantities of non-target analytes were extracted and $120^{\circ} \mathrm{C}$ was concluded to be the optimum temperature.

\section{Miscellaneous}

The extraction of some semivolatile organic pollutants (o-xylene, phenol, 2,4-dichlorophenol, naphthalene, diethyl phtalate, heptadecane, pyrene, endrin and DDT) from soil samples using PFE and Soxhlet extraction was reported $153 \%$. Blanks contained interfering peaks which co-eluted with certain target analytes. Some of these interferences could not be avoided using GC-MS in SIM mode since the target analyte and the interfering compound had major fragment ions in common. Pressurised fluid extraction blanks contained some peaks that were absent in the Soxhlet blanks. This suggested that reactions involving the soil organic matter were more important under the high temperature and pressure conditions of PFE. It was suggested that dissolved oxygen in the system might be responsible for some of the reactions and that the PFE blank might be reduced if the extraction solvents were degassed just prior to use.

Tomkins et al. 154/ extracted organosulfur and phosphorus containing analytes from spiked soil and concrete samples. While the recovery of organosulfur compunds was good $(95 \%)$, lower recoveries were obtained for organophosphonates $(60-80 \%)$. The authors suggested that organophosphonates were either more difficult to extract from both matrices than organosulfur species or they were partially degraded on the sample surfaces.

The influence of temperature $\left(25-200^{\circ} \mathrm{C}\right)$ and pressure $(700-2500 \mathrm{psi})$ on the PFE extraction of non-pesticidal organophosphorus hydraulic fluids from soil samples has been reported $/ 55 /$. The results were compared with Soxhlet extraction and SFE. Temperature had a minor effect on the extraction yields 
and best recoveries were obtained at $100^{\circ} \mathrm{C}$ (Figure 28a). It was suggested that high values of density and diffusivity improved recoveries, while better repeatability was obtained at lower temperatures. As higher temperatures increased sample changeover time, in order to allow the system to cool, $100^{\circ} \mathrm{C}$ was chosen as the extraction temperature. It was also found that higher pressures increased extraction yields (Figure 28b). The influence of pressure

(a)

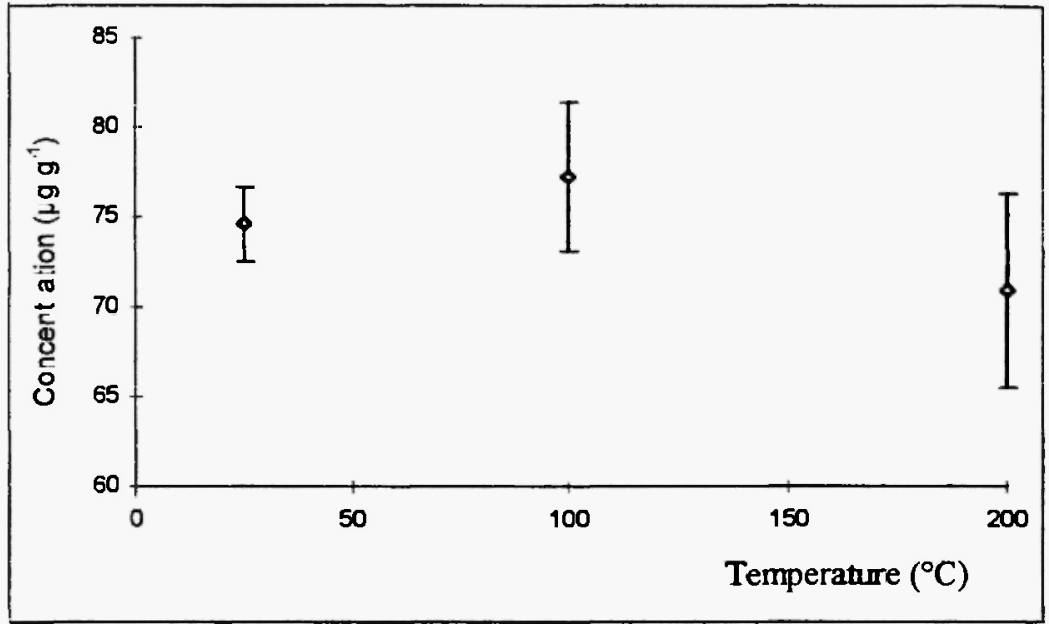

(b)

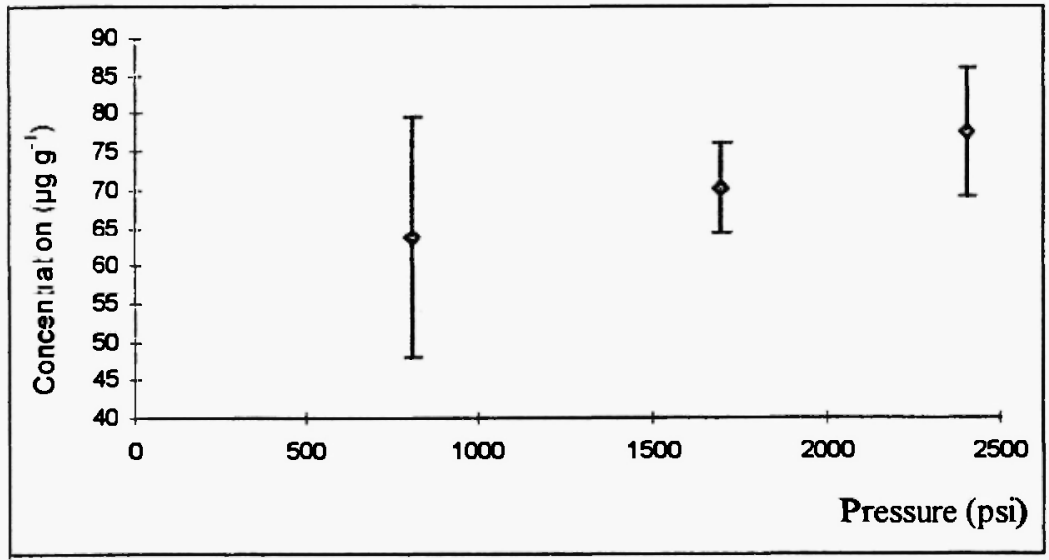

Fig. 28: Effect of temperature (a) and pressure on the extraction efficiencies of organophosphorus hydraulic fluids from soil samples. 
was attributable to the higher diffusivity of the solvent, which in turn enables penetration of the matrix, and hence solvation of the target analytes. Both SFE and PFE provided similar recoveries to those obtained by Soxhlet, but with shorter extraction times and smaller solvent volumes. However, better precision was obtained with Soxhlet extraction.

\section{CONCLUSIONS AND FUTURE DEVELOPMENTS}

The development of PFE for the extraction of organic compounds from environmental matrices is a welcome addition to the armoury of the analytical/environmental scientist. The additional advantages offered by PFE in terms of automation, use of small solvent volumes and rapid extraction times will eventually outweigh the disadvantage of the higher capital cost of the apparatus when compared to traditional approaches like Soxhlet extraction. However, even the high capital cost can be justified if the purchase of such equipment is viewed in terms of the higher sample throughput that can be achieved and the high capital costs of the chromatographic separation/detection systems that are (normally) used post-extraction. In terms of the overall operation of a commercial laboratory the high capital cost can be justified in terms of its considerable advantages.

The use of high temperature and pressure for extraction is obviously not only related to PFE. Other approaches that utilise these features, in conjunction with solvent extraction, are supercritical fluid extraction and microwave-assisted extraction. While both approaches have indeed been available commercially for a longer time than PFE (SFE since the late 1980's and MAE since the early 1990's), their acceptance has not necessarily been as widespread. This may largely be due to the limited range of applicability of SFE in terms of EPA methodology (currently only method 3561 and 3560 for PAHs and TPHs, respectively) and MAE which has only recently reached a proposed method status (method 3546). Nevertheless both approaches should not be ignored (or over-sold by manufacturers) in terms of their applicability to the extraction of organic compounds from environmental matrices.

NOTE: While pressurised fluid extraction (PFE) has been used throughout this article, other terms are found in the scientific literature, namely, pressurised liquid extraction (PLE) and accelerated solvent extraction (ASE). All are interconvertable terms, as they refer to the extraction of organic compounds by solvents under high temperature and pressure. 


\section{REFERENCES}

1. Test Methods for Evaluating Solid Waste, Method 3545, USEPA SW-846, 3rd ed., Update III, U.S. GPO, Washington DC, January, 1995.

2. Dionex, Accelerated solvent extraction seminar and workshop, 7 June 1995, Leeds.

3. B. Lesnik, Env. Lab., Dec/Jan, 27 (1994/95).

4. B.E. Richter, B.A. Jones, J.L. Ezell and N.L. Porter, Anal. Chem., 68, 1033 (1996).

5. CRC Handbook of Chemistry and Physics, 52nd Edition, D. R. Lide (Editor), CRC Press Inc, 1971-1972.

6. CRC Handbook of Chemistry and Physics, 76th Edition, D. R. Lide (Editor), CRC Press Inc, 1995-1996

7. J.R. Dean, A. Santamaria-Rekondo and E. Ludkin, Anal. Comm., 33, 413 (1996).

8. K.M. Meney, C.M. Davidson, D. Littlejohn, N.J. Cotton and B. Fields, Anal. Comm., 35, 173 (1998).

9. D.V. Kenny and S.V. Olesik, J. Chromatogr. Sci., 36, 66 (1998).

10. A. Kreisselmeier and H.W. Durbeck, J. Chromatogr., 775A, 187 (1997).

11. D. L. Massart, B. G. M. Vandeginste, S. N. Deming, Y. Michotte, and L. Kaufman, Chemometrics - A Textbook, Elsevier, Amsterdam, 1988.

12. N. Saim, J. R. Dean, Md. P. Abdullah, and Z. Zakaria, Anal. Chem., 70, 420 (1998).

13. M. M. Schantz, J. J. Nicholls and S. A. Wise, Anal. Chem., 69, 4210 (1997).

14. H. Obana, K. Kikuchi, M. Okihashi and S. Hori, Analyst, 122, 217 (1997).

15. P. Popp, P. Keil, M. Moder, A. Paschke and W. Thuss., J. Chromatogr., 774A, 203 (1997).

16. E. Bjorkland, S. Bowadt, T. Nilsson and L. Mathiasson., $J$. Chromatogr., 836A, 285 (1999).

17. D. L. Poster, M. M. Schantz, S. A. Wise and M. G. Vangel, Fresenius J. Anal. Chem., 363, 380 (1999).

18. L.J. Fitzpatrick and J.R. Dean, 21 st International Symposium on Capillary Chromatography and Electrophoresis, Park City, Utah, USA, 20-24 June 1999. 
19. R. F. Fedors, Polymer Eng. Sci., 14, 147 (1974).

20. C. M. Hansen, J. Paint Technol., 39, 105 (1967).

21. A. F. M. Barton, The Handbook of Solubility Parameters and other Cohesion Parameters, CRC Press Inc. Florida, 1983.

22. D. W. van Krevelen and P. J. Hoftzyer, Properties of Polymers; Their Estimation and Correlation with Chemical Structure, Elsevier, Amsterdam, 1976.

23. J.R. Dean, Anal. Commun., 33, 191 (1996).

24. J. L. Ezzell, B. E. Richter, W. D. Felix, S. R. Black and J. E. Miekle, $L C-G C, 13,390$ (1995).

25. V. Camel, A. Tanbute and M. Caude, J. Chromatogr., 693A, 101 (1995).

26. E. Conte, R. Milani, G. Morali and F Abballe, J. Chromatogr., 765A, 121 (1997).

27. S. P. Frost, J. R. Dean, K. P. Evans, K. Harradine, C. Cary, and M. H. I. Comber, Analyst, 122, 895 (1997).

28. B.J. Alloway and D.C. Ayres, Chemical Principles of Environmental Pollution, Blackie Academic and Professional, Glasgow, 1993.

29. O.P. Heemken, N. Theobald and B.W. Wenclawiak, Anal. Chem., 69, 2171 (1997).

30. N. Saim, J.R. Dean, Md. P. Abdullah and Z. Zakaria, J. Chromatogr., 791A, 361 (1997).

31. J.C. Chuang, S.W. Hannan and N.K. Wilson, Environ. Sci. Technol., 21, 798 (1987).

32. J.C. Chaung, S.W. Hannan and L.E. Silvon, EPA Report No. 600/54-87/039, 1988.

33. W.A. Korfmarcher, D.R. Natusch, D.R. Taylor, G. Mamantov and E.L. Wehry, Science, 207, 763 (1980).

34. D.V. Kenny and S.V.Olesik, J. Chromatogr. Sci., 36, 59 (1998).

35. B.E. Richter, J.L. Ezzell, D. Felix, K.A. Roberts and D.W. Later, America Lab., February, 24 (1995).

36. C.W. Chen, Y.Y. Wang and G.J.G. Wu, J. Chinese Chem. Society, 46, 245 (1999).

37. D. Jensen, F. Höfler, J. Ezzell and B. Richter, Polycyclic Aromatic Compounds, 9, 233 (1996).

38. J.D. Berset, M. Ejem, R. Holzer and P. Lischer, Anal. Chim. Acta, 383, 263 (1999).

39. F. Smedes and J. de Boer, Trends Anal. Chem., 16, 503 (1997). 
40. O. Zuloaga, N. Etxebarria, L.A. Fernandez and J.M. Madariaga, Trends Anal. Chem., 17, 642 (1998).

41. J.A. Nelder and R. Mead, Comput. J., 7, 308 (1965).

42. MultiSimplex (v 1.0), Berström and Oberg, Gullberna Park, Karlskrona, 1997.

43. K.D. Wenzel, A. Hubert, M. Manz, L. Weissflog, W. Engewald and G. Schüürmann, Anal. Chem., 70, 4827 (1998).

44. Dionex Application Notes ASE 313, 316, 318 and 320, Dionex Corp., Sunnyvale, CA, 1994.

45. B.E. Richter, J.L. Ezzell, D.E. Knowles, F. Hoefler, A.K.R. Mattulat, M. Scheutwinkel, D.S. Waddell, T. Gobran and V. Khurana, Chemosphere, 34, 975 (1997).

46. H. Bautz, J. Polzer and L. Stieglitz, J. Chromatogr., 815A, 231 (1998).

47. J.L. Ezzell, B.E. Richter, W.D. Felix, S.R. Black and J.E. Meikle, $L C-G C, 13,390$ (1995).

48. W.C. Brumley, E. Latorre, V. Kelliher, A. Marcus and D.E. Knowles, J. Liq. Chrom. Rel. Technol., 21, 1199 (1998).

49. S.M. Pyle and A.B. Marcus, J. Mass Spectrom., 32, 897 (1997).

50. E. Conte, R. Milani, G. Morali and F. Abballe, J. Chromatogr., 765A, 121 (1997).

51. M. Okihashi, H. Obana and S. Hori, Analyst, 123, 711 (1998).

52. S. Nemoto and S.J. Lehotay, J.Agric. Food Chem., 46, 2190 (1998).

53. J.A. Fisher, M.J. Scarlett and A.D. Scott, Environ. Sci. Technol., 31, 1120 (1997).

54. B.A. Tomkins, G.A. Sega and S.J. Macnaughton, Anal. Letters, 31, 1603 (1998).

55. M.D. David and J.N. Seiber, Anal. Chem., 68, 3038 (1996). 